\title{
Hepatic pathology and altered gene transcription in a murine model of acid ceramidase deficiency
}

\author{
Fabian P. S. $\mathrm{Yu}^{1,2} \cdot$ Salvatore Molino ${ }^{1} \cdot$ Jakub Sikora $^{3,4} \cdot$ Shauna Rasmussen $\mathbb{1}^{5} \cdot$ Jitka Rybova ${ }^{1} \cdot$ Everett Tate $^{1}$. \\ Aron M. Geurts ${ }^{5}$ - Patricia V. Turner ${ }^{6}$ - William M. Mckillop ${ }^{1}$ - Jeffrey A. Medin ${ }^{1,2,7,8,9}$
}

Received: 11 October 2018 / Revised: 4 April 2019 / Accepted: 6 May 2019 / Published online: 11 June 2019

(c) United States \& Canadian Academy of Pathology 2019

\begin{abstract}
Farber disease (FD) is a rare lysosomal storage disorder (LSD) characterized by systemic ceramide accumulation caused by a deficiency in acid ceramidase (ACDase). In its classic form, FD manifests with painful lipogranulomatous nodules in extremities and joints, respiratory complications, and neurological involvement. Hepatosplenomegaly is commonly reported, and severe cases of FD cite liver failure as a cause of early death. Mice homozygous for an orthologous patient mutation in the ACDase gene (Asahl $1^{\mathrm{P} 361 \mathrm{R} / \mathrm{P} 361 \mathrm{R}}$ ) recapitulate the classical form of human FD. In this study, we demonstrate impaired liver function and elevation of various liver injury markers in $A s a h 1^{\mathrm{P} 361 \mathrm{R} / \mathrm{P} 361 \mathrm{R}}$ mice as early as 5 weeks of age. Histopathology analyses demonstrated significant formation and recruitment of foamy macrophages, invasion of neutrophils, progressive tissue fibrosis, increased cell proliferation and death, and significant storage pathology within various liver cell types. Lipidomic analyses revealed alterations to various lipid concentrations in both serum and liver tissue. A significant accumulation of ceramide and other sphingolipids in both liver and hepatocytes was noted. Sphingolipid acyl chains were also altered, with an increase in long acyl chain sphingolipids coinciding with a decrease in ultra-long acyl chains. Hepatocyte transcriptome analyses revealed significantly altered gene transcription. Molecular pathways related to inflammation were found activated, and molecular pathways involved in lipid metabolism were found deactivated. Altered gene transcription within the sphingolipid pathway itself was also observed. The data presented herein demonstrates that deficiency in ACDase results in liver pathology as well as sphingolipid and gene transcription profile changes that lead to impaired liver function.
\end{abstract}

Supplementary information The online version of this article (https:// doi.org/10.1038/s41374-019-0271-4) contains supplementary material, which is available to authorized users.

$\triangle$ William M. Mckillop

monty.mckillop@mcw.edu

1 Department of Pediatrics, Medical College of Wisconsin, Milwaukee, WI, USA

2 Institute of Medical Science, University of Toronto, Toronto, ON, Canada

3 Rare Diseases Research Unit, Department of Pediatrics and Adolescent Medicine, Charles University, 1st Faculty of Medicine and General University Hospital, Prague, Czech Republic

4 Institute of Pathology, Charles University, 1st Faculty of Medicine and General University Hospital, Prague, Czech Republic

\section{Introduction}

Farber disease (FD) (OMIM \#228000), also known as Farber's lipogranulomatosis, or acid ceramidase (ACDase) deficiency, is an ultra-rare lysosomal storage disorder (LSD) caused by homozygous or compound heterozygous mutations in the ASAHI gene [1]. ACDase is a hydrolase that

5 Department of Physiology, Medical College of Wisconsin, Milwaukee, WI, USA

6 Department of Pathobiology, University of Guelph, Guelph, ON, Canada

7 Department of Biochemistry, Medical College of Wisconsin, Milwaukee, WI, USA

8 University Health Network, Toronto, ON, Canada

9 Department of Medical Biophysics, University of Toronto, Toronto, ON, Canada 
breaks down the bioactive sphingolipid ceramide into sphingosine (Sph) and a free fatty acid. To date, there have been 152 cases of FD reported in the literature [2]. While our understanding of the natural course of FD is incomplete, case reports suggest that FD can manifest along a wide clinical spectrum [3]. Patients with the classic severe FD variant will die during infancy, while patients with attenuated FD may live to early adulthood [1]. The most common clinical manifestations include: formation of subcutaneous nodules, joint contractures, and voice hoarseness $[1,4,5]$. Patients who develop more severe FD may also develop nervous system involvement, respiratory disease, and hepatosplenomegaly [5-8]. There is no known cure for FD. Hematopoietic stem cell transplantation (HSCT) may be an effective option for Farber patients who display minimal neurological involvement [9]. Beyond HSCT, most patients receive symptomatic treatment [1].

Several FD patient case reports document hepatomegaly during examination, as well as the presence of foamy histiocytes and ceramide accumulation in post-mortem liver tissue [4, 10-13]. Additionally, hepatic dysfunction is common in the severe visceral variant of FD [1, 14, 15]. In one such case, an infant was misdiagnosed with neonatal giant cell hepatitis and treated with a liver transplant before being properly diagnosed with FD [8]. However, aside from superficial descriptions in infrequent case reports, there has not been a detailed study performed on liver pathophysiology resulting from ACDase deficiency.

Proper sphingolipid homeostasis is vital for health, and insults to this tightly regulated balance result in a variety of disorders [16, 17]. This is apparent in FD and other LSDs where inherited lysosomal deficiencies lead to sphingolipid accumulation and pathogenesis. LSDs, such as Niemann-Pick types A and B, Gaucher disease, and GM1 gangliosidosis, all exhibit forms of liver disease; corresponding mouse models have been used to track disease progression and the extent of liver involvement [18-21].

In this study, we utilize the Asahl ${ }^{\mathrm{P} 361 \mathrm{R} / \mathrm{P} 361 \mathrm{R}}$ mouse model of ACDase deficiency that we previously generated [22]. Asahl ${ }^{\mathrm{P} 361 \mathrm{R} / \mathrm{P} 361 \mathrm{R}}$ mice have a reported FD patient mutation, proline $(\mathrm{P}) 362$ to arginine $(\mathrm{R})$, "knocked-in" to the corresponding murine Asahl locus (P361R) [22]. Homozygous Asahl ${ }^{\mathrm{P} 361 \mathrm{R} / \mathrm{P} 361 \mathrm{R}}$ mice exhibit a phenotype that recapitulates the clinical signs and symptoms seen in FD patients including; extensive inflammation, a reduction in lifespan, ceramide accumulation, pulmonary deficits, neurological pathology, and failure to thrive [22-26].

ACDase deficiency results in ceramide accumulation, an essential feature of FD. Ceramides and their metabolites are key constituents of membranes and regulate a multitude of cellular functions including inflammation, cell proliferation, and apoptosis [27-29]. Studies in more common disorders have shown that impairment of the ceramide pathway can result in significant downstream effects on the liver [30, 31]. Due to the role of ceramides and associated sphingolipids in hepatic health, in this study we performed a comprehensive evaluation of liver pathology and examined the gene transcription profile in Asahl ${ }^{\mathrm{P} 361 \mathrm{R} / \mathrm{P} 361 \mathrm{R}}$ mouse hepatocytes. We report here that ACDase deficiency leads to perturbed liver function. This is characterized by significant inflammation, liver injury, altered lipid profiles and sphingolipid accumulation, and changes in gene transcription that affect inflammation as well as lipid homeostasis. Taken together, we demonstrate that ACDase deficiency results in significant molecular and physiological alterations leading to impaired liver function and hepatocyte cell death.

\section{Materials and methods}

\section{Animal use, breeding, and genotyping}

All animal procedures and experiments were approved and carried out in adherence with the policies set forth by the University Health Network Animal Care Committee and the Medical College of Wisconsin Institutional Animal Care and Use Committee. To generate homozygous Asahl ${ }^{\mathrm{P} 361 \mathrm{R} / \mathrm{P} 361 \mathrm{R}}$ mice, we crossed Asahl ${ }^{+/ \mathrm{P} 361 \mathrm{R}}$ heterozygotes as previously reported [22]. Genotyping was conducted by PCR performed on DNA from mouse ear notches as previously reported [22].

\section{Animal liver weight and collagen assay}

Mice were weighed just prior to being euthanized by $\mathrm{CO}_{2}$ gas inhalation. Livers were immediately removed, weighed, and collected on dry ice for further analyses. To determine collagen levels in liver tissue, a Sircol Collagen Assay (Biocolor Ltd, United Kingdom) was performed following the manufacturer's instructions.

\section{Serum chemistry and ELISAs}

For serum biochemistry, terminal cardiac puncture was used to collect blood into serum separator SST microtainers (BD Biosciences, San Jose, CA). Sample tubes were inverted 8-10 times immediately after collection and held at room temperature for $30 \mathrm{~min}$ prior to centrifugation at $1200 \times g$ for $10 \mathrm{~min}$. Serum was collected and immediately stored at $-80^{\circ} \mathrm{C}$ until use. All samples that contained significant hemolysis were excluded. Serum metabolites and enzymes were measured using both the VetScan Comprehensive Diagnostic Profile and Mammalian Liver Profile reagent rotors (Abaxis, Union City, CA) on the Abaxis VetScan VS2 chemistry analyzer (Abaxis, Union City, CA) following the manufacturer's instructions. Amino aspartate 
transferase (AST) levels in serum were measured with the AST ELISA kit (Cloud-Clone Corp., Wuhan China) following the manufacturer's instructions.

\section{Western blotting}

Mice were deeply anesthetized with isoflurane. Surgical scissors were used to expose the heart and pleural cavity by cutting through the diaphragm and ribs on both sides of the sternum. The heart was excised, and the liver immediately flash frozen in $\mathrm{pH} 8$ RIPA buffer $(50 \mathrm{mM}$ Tris, $150 \mathrm{mM}$ $\mathrm{NaCl}, 1 \%$ Triton $\mathrm{X}-100,1 \%$ sodium deoxycholate, $0.1 \%$ SDS, $1 \mathrm{mM}$ EDTA) containing HALT Protease and Phosphatase Inhibitor Cocktail (Thermo Scientific). Samples were homogenized using a Bullet Blender Storm 24 (Next Advance, Troy, NY) tissue homogenizer with $0.5 \mathrm{~mm}$ zirconium oxide beads (Next Advance). Lysates were cleared by centrifugation and stored at $-80^{\circ} \mathrm{C}$. Protein concentration was determined using a BCA assay (Thermo Scientific). Ten microgram of each sample was resolved on $10 \%$ SDS-page and transferred onto PVDF membrane for western blotting. Primary antibodies used: rabbit monoclonal specific for phosphorylated-STAT3 (9145, Cell Signaling Technologies), rabbit monoclonal specific for total STAT3 (4904, Cell Signaling Technologies), rabbit monoclonal specific for phosphorylated-NF-кB p65 (3033, Cell Signaling Technologies), rabbit monoclonal specific for total NF-kB p65 (8242, Cell Signaling Technologies), mouse HRP-conjugated monoclonal specific for $\beta$-actin (A3854, Sigma-Aldrich, St. Louis, MO). Secondary antibody used: HRP-conjugated anti-Rabbit IgG (A6154, Sigma-Aldrich). Immunoreactivity was visualized with enhanced chemiluminescence substrate (Thermo Scientific) on a ChemiDoc MP (Bio-Rad Laboratories, Inc, Des Plaines, IL). Band densitometry was quantified using ImageJ software v.1.51 (NIH). Total STAT3, phosphorylated

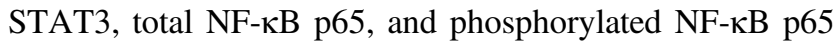
were normalized to $\beta$-actin loading controls. Normalized STAT3, p-STAT3, NF-кB p65, and p-NF-кB p65 from Asah1 ${ }^{\mathrm{P} 361 \mathrm{R} / \mathrm{P} 361 \mathrm{R}}$ mice were expressed relative to normalized STAT3, p-STAT3, NF-кB p65, and p-NF- $\kappa$ B p65 from Asahl $^{+/+}$mice.

\section{Pathology and immunohistochemistry}

Following euthanasia, cardiac perfusion was conducted with ice-cold PBS via a $24 \mathrm{G}$ needle. Liver specimens were immediately fixed in $10 \%$ phosphate-buffered formalin for 24-48 h. Liver specimens were then trimmed, embedded in paraffin wax, and sectioned at $4 \mu \mathrm{m}$. Liver sections were stained with hematoxylin and eosin (H\&E), Masson's trichrome, and reticulin by standard techniques. For liver immunohistochemistry (IHC), the following primary antibodies were used: anti-mouse neutrophil (Ly-6B.2) clone 7/4 (Cedarlane, Burlington, Canada) and rat antimouse Mac-2 (Galectin-3) clone M3/38 (Cedarlane), rabbit anti-cleaved caspase-3 (Cell Signaling Technology, Danvers, MA), and rabbit anti-Ki-67 (Thermo Scientific). In situ detection of cell death was performed via a Terminal deoxynucleotidyl transferase (TdT) dUTP Nick-End Labeling (TUNEL) assay (Promega, Madison, WI). The following secondary antibodies and reagents were then used to detect primary antibodies and TUNEL: biotinylated rabbit anti-rat $\operatorname{IgG}$ (Vector Laboratories, Burlingame, CA); biotinylated goat anti-rabbit IgG (Vector Laboratories); biotinylated goat anti-rat IgG (Vector Laboratories); biotinylated donkey anti-chicken IgG (Jackson ImmunoResearch USA, West Grove, PA); biotinylated donkey anti-rabbit IgG (ImmunoResearch); avidin-biotin/HRP (Vector Laboratories); DAB kit (Vector Laboratories), and Vectastain Elite ABC kit (Vector Laboratories). Histology slides were scanned on the Aperio AT2 histology slide scanner (Leica Biosystems, Buffalo Grove, IL) or NanoZoomer 2.0-HT histology slide scanner (Hamamatsu Photonics, Ichinocho, Japan). Scanned micrographs were analyzed with Aperio ImageScope analysis software (Leica Biosystems, Buffalo Grove, IL).

\section{Histopathology evaluation}

H\&E-stained liver slides derived from $\mathrm{Asahl}^{+/+}$mice and Asahl ${ }^{\mathrm{P} 361 \mathrm{R} / \mathrm{P} 361 \mathrm{R}}$ mice at 3,5, 7, and 9 weeks of age were analyzed for liver pathology. An injury score was developed that encompassed four main parameters: (1) histiocytic abnormality [0-normal/none, $1-$ minimal $(<5 \%), 2-$ mild (5-10\%), 3-moderate (>10-25\%, scattered multinucleated giant cells), 4-marked ( $>25 \%$, positive for histiocytic clusters within vessels, endothelial cells with lipid inclusions, and mononuclear giant cells)]; (2) neutrophilic infiltrates $[(0-$ normal/none, $1-$ minimal $(<5 \%$ section affected), 2-mild (5-10\%), 3-moderate (>10-25\%), and 4-marked (>25\%)]; (3) fibrosis [(0-normal/none, 1-minimal (focal), 2-mild (>5-10\%), 3-moderate (>10-25\%), and 4-marked ( $>25 \%$, periportal fibrosis along portal triads, and bridging fibrosis)]; and (4) hepatocellular cytoplasmic vacuolation $[(0-$ normal/none, 1 -mild microvesiculation $(<10 \%)$ or sporadic single cell necrosis, 2-moderate microvesiculation (10-25\%), 3generalized microvesiculation ( $>25-50 \%$ ), and 4-diffuse microvesiculation $(>50) \%$ ]. The injury score was evaluated by a pathologist (PVT) blinded to the experimental groups. A total of three animals per genotype and age group were scored. The sum of the four parameters was calculated as an individual liver injury score; the age group injury score was calculated by averaging the three individual liver scores for each genotype. 


\section{Quantitation of cell death and proliferation}

Micrographs from Ki67- and cleaved caspase-3 (Casp-3)stained slides were analyzed using the Aperio IHC Nuclear Image Analysis algorithm (Leica Biosystems). In brief, four separate liver samples were collected from $\mathrm{Asahl}^{+/+}$mice and $A s a h 1^{\mathrm{P} 361 \mathrm{R} / \mathrm{P} 361 \mathrm{R}}$ mice at both 5 weeks and 9 weeks of age. Tissues were prepared as described above. Three consecutive sections per animal were obtained and stained for Ki67 and Casp-3. Image analyses were performed on 10 random non-overlapping fields $(250 \times 450 \mu \mathrm{m})$ per section. A section average was obtained from 10 individual fields and a total animal value was calculated from the section averages. Data from the algorithm were expressed as a percentage of positive nuclear staining.

\section{Transmission electron microscopy}

Post-euthanasia, 8-9-week-old mice were perfused transcardially with $4 \%$ paraformaldehyde (PFA). Liver tissue was collected and stored in 4\% PFA for $48 \mathrm{~h}$. Multiple liver samples $\left(\sim 1.0-1.5 \mathrm{~mm}^{3}\right)$ were trimmed from the right lateral, median, and left lateral lobes of each animal and processed for transmission electron microscopy (TEM) as previously described [25].

\section{Murine liver perfusion and hepatocyte isolation}

Liver perfusion and hepatocyte isolation was adapted from Azuma and colleagues [32]. Briefly, 5-week-old AsahI ${ }^{+/+}$ mice and $A s a h 1^{\mathrm{P} 361 \mathrm{R} / \mathrm{P} 361 \mathrm{R}}$ mice were anesthetized with $5 \%$ isoflurane in $100 \%$ oxygen and opened to expose the liver and portal vein. Prior to perfusion, the portal vein was cannulated with a $26 \mathrm{G} \mathrm{3/4}$ inch IV catheter (Zoetis, Inc., Parsippany-Troy, NJ) connected to a Watson-Marlow 323 S/D peristaltic pump (Watson-Marlow Fluid Technology Group., Wilmington, MA). Once the catheter was inserted, the vena cava was cut and perfused. The liver was first flushed with Solution 1: 40-50 ml of Earle's balanced salt solution (EBSS) (Thermo Scientific) supplemented with 1x EDTA (Thermo Scientific) and 1X HEPES (Thermo Scientific) at $40{ }^{\circ} \mathrm{C}$ for $10 \mathrm{~min}$. The liver was next flushed with Solution 2: 20-30 $\mathrm{ml}$ of EBSS containing calcium and magnesium (Thermo Scientific) with 1x HEPES at $40{ }^{\circ} \mathrm{C}$ for 3-5 min. Lastly, the liver was flushed with Solution 3: 40-50 $\mathrm{ml}$ of Solution 2 supplemented with $1 \mathrm{~mL}$ of Liberase (Roche Diagnostics., Indianapolis, IN) at 26 Wunsch units/ $\mathrm{mL}$ at $40{ }^{\circ} \mathrm{C}$ for $10 \mathrm{~min}$. Once digested, the liver was excised and transferred into a Petri dish containing Solution 2 where connective tissue was removed manually. The digested liver was then transferred to a new Petri dish containing $10-15 \mathrm{ml}$ of cold hepatocyte culture medium (DMEM, 10\% FCS, 1\% Pen-Strep, 1\% Glutamine, and
$0.1 \% 1 \mathrm{M}$ HEPES) and minced. The tissues and cell suspensions were then transferred into a $50 \mathrm{ml}$ conical tube and allowed to settle prior to filtering the supernatant through a $100 \mu \mathrm{m}$ cell strainer. The suspension was further washed and passed through a $100 \mu \mathrm{m}$ cell strainer with $10-15 \mathrm{ml}$ of hepatocyte culture media. A total of $50 \mathrm{ml}$ of filtered cells were collected. The collected cells were then passed once more through a $70 \mu \mathrm{m}$ cell strainer and spun at $300 \times g$ for $3 \mathrm{~min}$ at $4{ }^{\circ} \mathrm{C}$. The cell pellet was resuspended in $5 \mathrm{ml}$ of hepatocyte culture medium and counted using Trypan Blue exclusion with the Countess II FL automated cell counter (Life Technologies, Carlsbad, CA). Two and a half million cells were seeded in $25 \mathrm{~cm}^{2}$ tissue culture flasks and incubated at $37{ }^{\circ} \mathrm{C}$ with $5 \% \mathrm{CO}_{2}$. After an overnight incubation, cells were washed two times with PBS to eliminate cellular debris before further analyses.

\section{Flow cytometry analyses}

Flow cytometry was performed on liver and hepatocyteenriched culture samples. To obtain a single cell suspension, liver cells were forced through a $40 \mu \mathrm{m}$ nylon cell strainer in PBS with 2\% fetal calf serum (FCS). Cells were collected, washed, resuspended in PBS with $2 \%$ FCS, and counted on a hemocytometer. Liver cell- and hepatocyteenriched cultures were stained for $30 \mathrm{~min}$ at $4{ }^{\circ} \mathrm{C}$ with CD11b (Mac-1) FITC (Biolegend; M1/70) antibodies to assess for monocytes/macrophages. Flow cytometry was performed using FACSDiva software (BD Biosciences) on either Fortessa or ARIA II (BD Biosciences) cytometers. Data was analyzed using FlowJo software (Tree Star Inc, Ashland, OR).

\section{RNA isolation, library preparation for RNASeq, and sequencing}

To analyze the transcriptome of 5-week-old Asahl ${ }^{\mathrm{P} 361 \mathrm{R} /}$ P361R mouse hepatocyte-enriched cultures, an RNAseq approach was employed. First, total RNA was isolated from $\sim 2 \times 10^{6}$ cells using TRIzol (Life Technologies). RNA was purified using RNeasy spin columns (Qiagen, Crawley, UK) according to the manufacturer's instructions. Total RNA integrity was confirmed using an Agilent 2100 Bioanalyzer (Agilent Technologies, Santa Clara, CA). The RNAseq library preparation and sequencing was performed by the Sequencing Core at MCW as follows: libraries were prepared from $100 \mathrm{ng}$ of total RNA using a Truseq Stranded mRNA Kit on the Illumina NeoPrep automated library preparation instrument (Illumina Inc., San Diego, CA). The quality of the prepared libraries was analyzed using the DNA1000 assay on the Agilent Bioanalyzer 2100 (Agilent Technologies) and quantified via quantitative Real-Time PCR using the Kapa Biosystems Library Quantification Kit 
(Kapa Biosystems, Inc., Wilmington, MA) and a Bio-Rad CFX384 Real-Time PCR instrument (Bio-Rad Laboratories, Inc, Des Plaines, IL). Libraries were diluted and pooled at equimolar ratios and sequenced with a $1 \times 50$ single-read Miseq run to assess for cluster density and index distribution. The amplicon pool concentration was normalized and then sequenced in a HiSeq 2500 Flowcell (Illumina technology) with a single run. $2 \times 125 \mathrm{bp}$ pairedend sequencing was performed across 2 lanes at a sample density of eight samples per lane. Upon completion of the sequencing run, the data were demultiplexed using Illumina's Bcl2Fastq v1.8.4 conversion software (Illumina Inc).

\section{Quantitative real-time PCR}

The RNAseq results were validated by confirming the RNA expression of several high-scoring genes using quantitative real-time PCR. TRIzol was used to isolate total RNA from new cell samples. After reverse-transcription, real-time PCR was conducted with Applied Biosystems ${ }^{\mathrm{TM}}$ PowerUp ${ }^{\mathrm{TM}}$ SYBR ${ }^{\text {TM }}$ Green Master Mix (Thermo Scientific), following the manufacturer's instructions, on a ViiA7 System (Applied Biosystems, Life Technologies Cooperation, Carlsbad, CA, USA). The primer sequences that were used are provided in Table $\mathrm{S} 1$.

\section{Sphingolipids in liver tissue and hepatocytes}

Liver tissue ( $300 \mathrm{mg})$ was homogenized in $\sim 600 \mu \mathrm{l}$ of $2 \%$ CHAPS with a Bullet Blender (Next Advance, Inc., Troy, $\mathrm{NY)}$ using $0.5 \mathrm{~mm}$ zirconium oxide beads. Lipids were extracted from $50 \mu \mathrm{l}$ of tissue lysate with $200 \mu \mathrm{l}$ isopropanol. The following internal standards were used for sphingolipid measurements: ceramide, $100 \mathrm{ng}$ (d18:1/ 22:0) $\mathrm{d}_{4}$ (Medical University of South Carolina (MUSC) Lipidomics Core, Charleston, SC); monohexosylceramide (MHC), $100 \mathrm{ng}$ (d18:1/17:0) (Avanti Polar Lipids Inc., Alabaster, AL); sphingomyelin (SM), 1000 ng (d18:1/17:0) (Avanti Polar Lipids Inc.); $100 \mathrm{ng}$ ceramide-1-phosphate (C1P) (d18:1/16:0), (d18:1/24:0) and (d18:1/24:1) (Matreya Inc., Pleasant Gap, PA) (Avanti Polar Lipids Inc.); and sphingosine (Sph), 100 ng (Avanti Polar Lipids Inc.) [33].

For enriched hepatocytes, $\sim 2.0 \times 10^{6}-3.0 \times 10^{6}$ cells were lysed in $200 \mu \mathrm{l}$ of PBS by passing through a $28 \mathrm{G}$ needle 15-20 times. Lipids were extracted from $100 \mu \mathrm{l}$ of each cell homogenate with $400 \mu \mathrm{l}$ of isopropanol. The supernatant from that extraction was reconstituted with $250 \mu \mathrm{l}$ of water for LC-MS/MS analysis. The following internal standards were used for sphingolipid measurements: ceramide, $100 \mathrm{ng}(\mathrm{d} 18: 1 / 17: 0) \mathrm{d}_{4}$ (MUSC Lipidomics Core); MHC, $10 \mathrm{ng}$ (d18:1/17:0) (Avanti Polar Lipids Inc.); SM, 300 ng (d18:1/17:0) (Avanti Polar Lipids Inc.); and C1P, $100 \mathrm{ng}$ (d18:1/12:0) (Avanti Polar Lipids
Inc.). Liver and hepatocyte analyses were performed using the Shimadzu 20AD HPLC system and a Leap PAL autosampler coupled to a triple quadrupole mass spectrometer (API-4000: Applied Biosystems) operated in the Multiple Reaction Monitoring (MRM) mode. The positive ion electrospray ionization (ESI) mode was used for detection of sphingolipids. Samples were injected in duplicate for data averaging. Data processing was conducted with Analyst 1.5.1 (Applied Biosystems). The relative quantification of sphingolipids was expressed as the peak area ratios of the analytes to the corresponding internal standards. The data are presented as fold-change relative to the averaged sphingolipid values detected in samples from control Asah1 ${ }^{+/+}$mice.

\section{Measurement of lipids in liver and serum}

Following euthanasia, serum and liver tissue were collected from mice that had been fasted overnight $(\sim 12 \mathrm{~h})$. Liver samples were homogenized and lipids were extracted from $50 \mu \mathrm{l}$ of serum and liver lysates as described above. The following internal standards were used to measure lipids: phosphatidylcholine (PC) (14:1-14:1) (Avanti Polar Lipids Inc,); triglyceride (TG) (17:0-17:0-17:0) (Avanti Polar Lipids Inc,); free fatty acid (FFA) $d_{4}$ (16:0) (Avanti Polar Lipids Inc,). Internal standards were added to the samples before extraction. Extracted FFA samples were further derivatized by aminomethyl phenyl pyridium (AMPP) into FA-AMPP derivatives to obtain increased sensitivity in MS.

Free cholesterol (FC) and cholesteryl esters were extracted with $200 \mu \mathrm{l}$ isopropanol. After vortexing and centrifugation, $10 \mu \mathrm{l}$ of that supernatant was used for total cholesterol (TC) analyses and the remaining supernatant was used for FC determination. Five microgram of deuterated cholesterol-d7 (Avanti Polar Lipids Inc,) was added as an internal standard for FC and TC samples prior to lipid extraction. Measurement of lipids was performed using a Shimadzu 10 A HPLC system and a Shimadzu SIL-20AC HT autosampler coupled to a Thermo Scientific TSQ Quantum Ultra triple quadrupole mass spectrometer (API4000: Applied Biosystems) operated in MRM mode for PC, FFA, TC and SRM mode under ESI (+) for TC and FC samples. Data processing was conducted with Analyst 1.5.1 (Applied Biosystems).

\section{Statistical analyses}

Data are expressed as means \pm standard error. Unless otherwise stated, data were analyzed with Student's $t$-test. Serum biochemistry, ELISA, and FACS read-outs were analyzed with a one-way ANOVA followed by Tukey's post-hoc test. All statistics were analyzed using GraphPad 
Prism 6.0 (GraphPad Software Inc, La Jolla, CA). Significant differences are expressed in the Figures as $* p<$ 0.05 , $* * p<0.01$, and $* * * p<0.001$. For RNAseq, the Benjamini-Hochberg method was used to control for false discovery rates. False discovery rates of 0.05 were considered significant. The $95 \%$ confidence interval was considered significant.

\section{Results}

\section{Hepatomegaly and liver injury}

Asahl $1^{\mathrm{P} 361 \mathrm{R} / \mathrm{P} 361 \mathrm{R}}$ mice displayed a phenotype analogous to that which we previously reported [22]. Asahl P361R/P361R $^{\text {[ }}$ mice demonstrated decreased body weight compared to AsahI $^{+/+}$mice by 3 weeks of age (Fig. 1a). Livers from $A s a h 1^{+/+}$mice were significantly heavier than those from Asahl $1^{\mathrm{P} 361 \mathrm{R} / \mathrm{P} 361 \mathrm{R}}$ mice from 7 weeks onward (Fig. 1b). Normalizing liver tissue-weight to body-weight revealed significant hepatomegaly in Asahl $1^{\mathrm{P} 361 \mathrm{R} / \mathrm{P} 361 \mathrm{R}}$ mice as early as 3 weeks of age (Fig. 1c).

Analyses of common liver injury markers in serum revealed significantly higher serum levels of aspartate aminotransferase, alanine aminotransferase, and alkaline

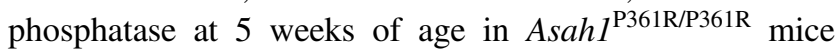
(Fig. 1d-f). Gamma-glutamyl transferase, an enzyme that is often analyzed in conjunction with alkaline phosphatase to distinguish bone-versus-liver injury, was also significantly increased in Asahl ${ }^{\mathrm{P} 361 \mathrm{R} / \mathrm{P} 361 \mathrm{R}}$ mice compared to Asahl ${ }^{+/+}$ mice at 9 weeks of age (Fig. 1g) further confirming primary hepatocyte involvement. No significant changes were detected in total bilirubin between $A s a h 1^{+/+}$mice and Asahl ${ }^{\mathrm{P} 361 \mathrm{R} / \mathrm{P} 361 \mathrm{R}}$ mice; however, total bilirubin did trend upward between 5 weeks of age and 9 weeks of age (Fig. 1h). Both blood urea nitrogen and bile acids were also found to be significantly increased in samples from Asahl ${ }^{\mathrm{P} 361 \mathrm{R} / \mathrm{P} 361 \mathrm{R}}$ mice at 9 weeks of age compared to samples from Asahl $^{+/+}$mice (Fig. 1i, j), again emphasizing hepatocellular functional deficits. A reduction in serum albumin and total cholesterol levels was only detected between $A_{s a h l^{+/+}}$mice and Asahl $1^{\mathrm{P} 361 \mathrm{R} / \mathrm{P} 361 \mathrm{R}}$ mice at 9 weeks of age (Fig. 1k, 1). Glucose levels in serum were significantly decreased in both 5-week-old and 9-week-old Asahl ${ }^{\mathrm{P} 361 \mathrm{R} / \mathrm{P} 361 \mathrm{R}}$ mice compared to controls. Creatinine, a commonly used indicator of renal function, and troponin, a protein marker for cardiac health, were unchanged between Asahl ${ }^{+/+}$mice and Asahl ${ }^{\mathrm{P} 361 \mathrm{R} / \mathrm{P} 361 \mathrm{R}}$ mice (Fig. 1n, o).

\section{Liver pathology and cellular infiltration}

Hematoxylin and eosin (H\&E) staining of Asahl P361R/P361R liver sections revealed significant and progressive macrophage and neutrophil infiltration in comparison to control AsahI ${ }^{+/+}$liver sections (Fig. 2a-e). Macrophages in Asahl ${ }^{\mathrm{P} 361 \mathrm{R} / \mathrm{P} 361 \mathrm{R}}$ livers displayed a pale eosinophilic and foamy cytoplasm (Fig. 2e). Multifocal, coalescing accumulations of foamy macrophages were seen throughout the parenchyma and surrounding vessels (Fig. 2e); hepatic sinusoidal macrophages (Kupffer cells) also exhibited a foamy appearance (Fig. 2e). On occasion, clusters of 3-4 foamy macrophages together with mild neutrophilic infiltrates formed granulomas disrupting the hepatocellular trabeculae (Fig. 2e). Within these aggregates, single cell necrosis was often observed (Fig. 2e).

Immunohistochemistry (IHC) for Cathepsin D (CathD), a lysosomal marker, demonstrated cytoplasmic labeling in $A s a h 1^{\mathrm{P} 361 \mathrm{R} / \mathrm{P} 361 \mathrm{R}}$ samples as early as 3 weeks of age (Fig. 2b). CathD labeling was present within the vesiculated cytoplasmic material and localized to foamy macrophages by 9 weeks of age in $A s a h 1^{\mathrm{P} 361 \mathrm{R} / \mathrm{P} 361 \mathrm{R}}$ livers (Fig. 2e). To further characterize the extent of macrophage and neutrophil infiltration, IHC with antibodies specific for macrophage Mac-2 (galectin-3) and neutrophils was conducted on liver sections from both $A s a h 1^{+/+}$mice and Asahl ${ }^{\mathrm{P} 361 \mathrm{R} / \mathrm{P} 361 \mathrm{R}}$ mice (Fig. 2a-e). Increased inflammation was visible by 3 weeks of age in sections from Asahl ${ }^{\mathrm{P} 361 \mathrm{R} / \mathrm{P} 361 \mathrm{R}}$ livers (Fig. 2b). Between 5 weeks of age and 7 weeks of age, liver sections from Asahl $^{\mathrm{P} 361 \mathrm{R} / \mathrm{P} 361 \mathrm{R}}$ mice displayed increased neutrophil and macrophage aggregation (Fig. 2c, d). Macrophages increased in size and cytoplasmic vesiculation was more pronounced as the mice aged. By 9 weeks of age, Asahl ${ }^{\mathrm{P} 361 \mathrm{R} / \mathrm{P} 361 \mathrm{R}}$ mice displayed extensive neutrophil and macrophage infiltration (Fig. 2e).

\section{Hepatocellular storage pathology}

Transmission electron microscopy (TEM) was conducted on liver sections from AsahI $1^{+/+}$mice and AsahI $I^{\mathrm{P} 361 \mathrm{R} / \mathrm{P} 361 \mathrm{R}}$ mice (Fig. 3). Ultrastructure analyses of liver sections from Asahl ${ }^{+/+}$control mice demonstrated normal cytology (Fig. 3a). Hepatocytes from 9-week-old Asahl $1^{\mathrm{P} 361 \mathrm{R} / \mathrm{P} 361 \mathrm{R}}$ mice displayed excessive collagen fibers and atypical macrophages containing abnormal cytoplasmic storage vacuoles, fine granular-fibrillary content, and curvilinear tubular bodies (CTB), also known as Farber bodies (Fig. 3b). Kupffer cells in Asahl $1^{\mathrm{P} 361 \mathrm{R} / \mathrm{P} 361 \mathrm{R}}$ liver sinusoids demonstrated a similar storage pathology (Fig. 3d). Asah1 $1^{\mathrm{P} 361 \mathrm{R} / \mathrm{P} 361 \mathrm{R}}$ liver endothelial cells also accumulated CTB-like storage material (Fig. 3d). Hepatocytes in sections from $\mathrm{Asahl}^{+/+}$control livers displayed normal cytology (Fig. 3c, e); in contrast, hepatocytes in sections from Asahl ${ }^{\mathrm{P} 361 \mathrm{R} / \mathrm{P} 361 \mathrm{R}}$ livers displayed numerous cytoplasmic storage vacuoles (Fig. 3f, g). These abnormal hepatocyte storage vacuoles were smaller and less abundant than those 

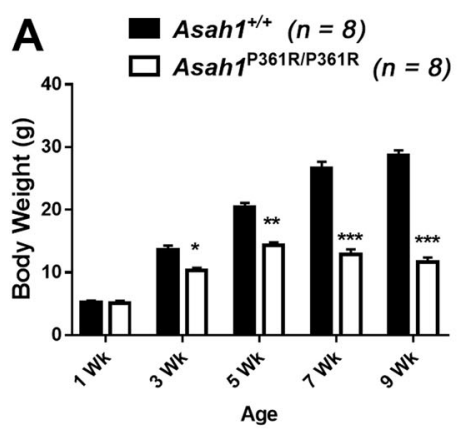

D

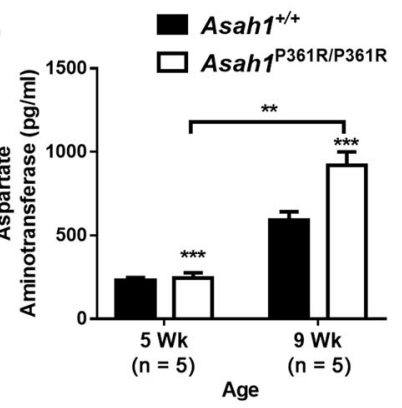

G

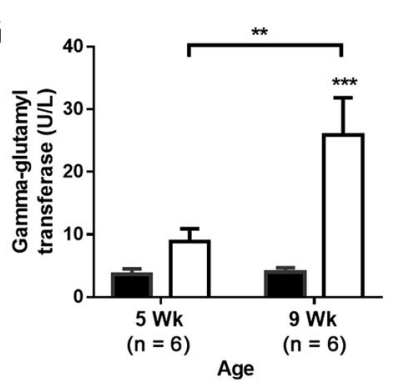

$\mathbf{J}$

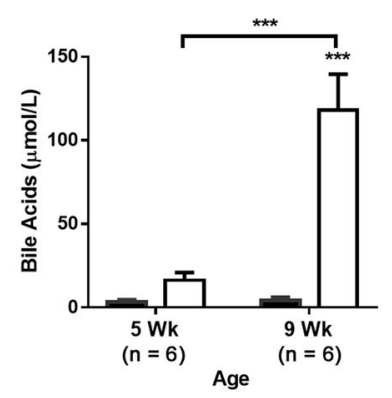

M

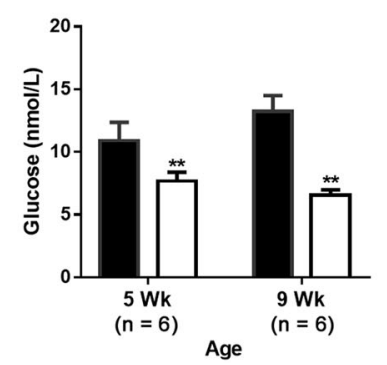

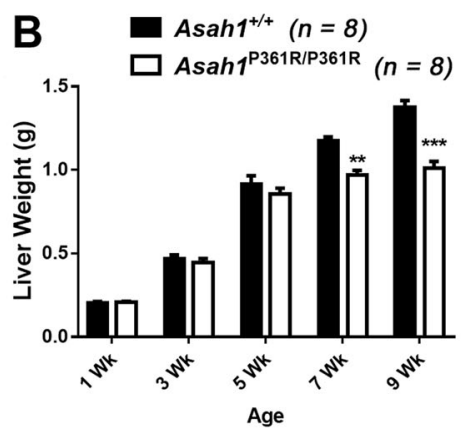

E

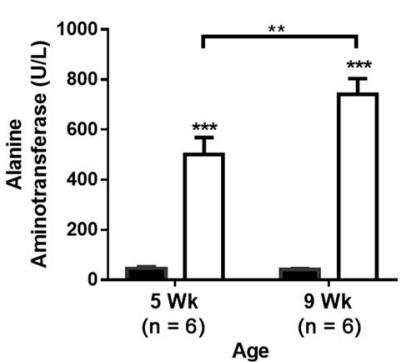

H

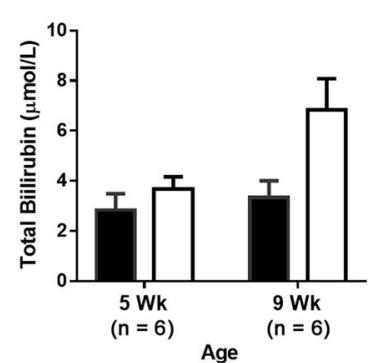

$\mathbf{K}$

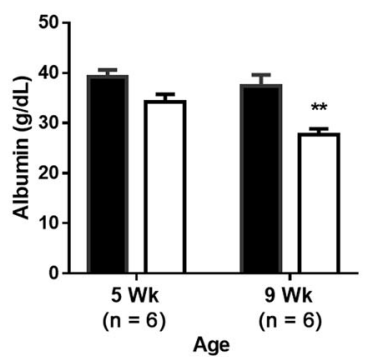

$\mathbf{N}$

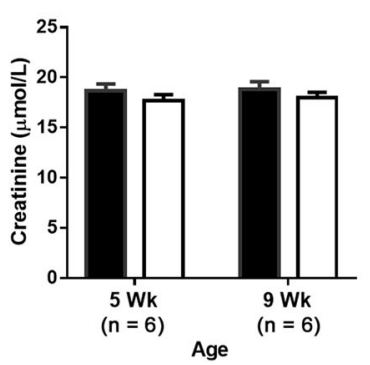

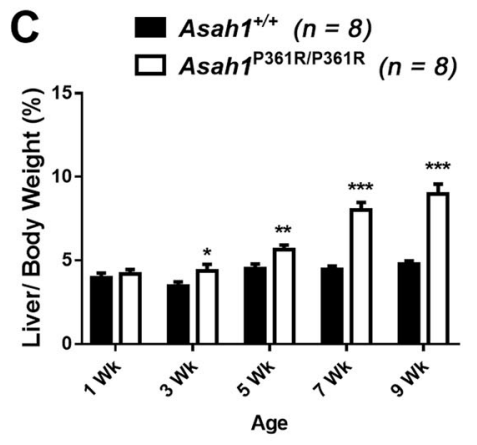

$\mathbf{F}$

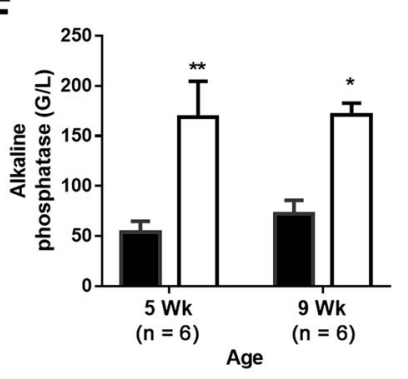

I

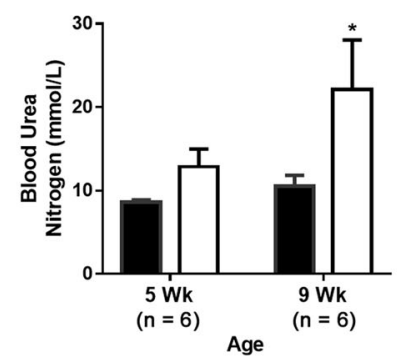

$\mathbf{L}$

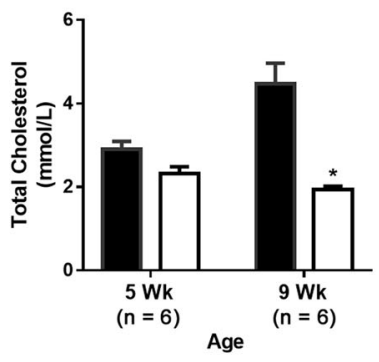

O

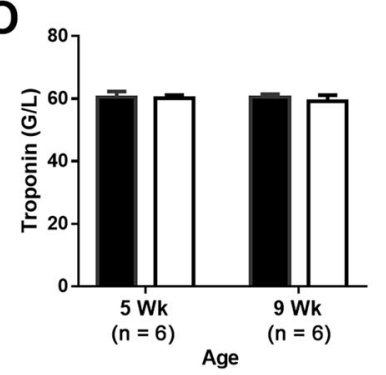

seen in macrophage and Kupffer cells in the same mice. Further analyses of the liver sinusoids demonstrated abnormal storage vacuoles in hepatic stellate (Ito) cells in
Asahl ${ }^{\mathrm{P} 361 \mathrm{R} / \mathrm{P} 361 \mathrm{R}}$ mice (Fig. S1B). Lastly, within the bile

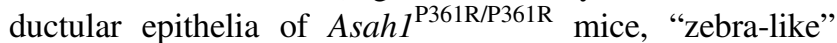
storage material was observed (Fig. S1D). 
Fig. 1 Hepatomegaly, liver injury, and perturbed serum metabolites in Asah1 $1^{\mathrm{P} 361 \mathrm{R} / \mathrm{P} 361 \mathrm{R}}$ mice. Body-weight measurements of $A s a h 1^{+/+}$mice and $A s a h 1^{\mathrm{P} 361 \mathrm{R} / \mathrm{P} 361 \mathrm{R}}$ mice at varying ages ( $n=8$ for both genotypes) (a). Liver weight corresponding to age ( $n=8$ per genotype) (b). Liver weight measured as a percentage of body weight corresponding to age ( $n=8$ per genotype) (c). ELISA for aspartate aminotransferase (AST) in serum from 5-week-old and 9-week-old mice ( $n=5$ per genotype) (d). Liver specific and general metabolites as well as enzymes were analyzed in serum samples from 5-week-old and 9-week-old mice for each genotype. Analytes from the biochemistry panels include alanine aminotransferase (ALT) (e), alkaline phosphatase (ALP) (f), gammaglutamyl transferase (GGT) (g), total bilirubin (TB) (h), blood urea nitrogen (BUN) (i), bile acids (BA) (j), albumin (k), total cholesterol (TC) (I), glucose (m), creatinine (n), and troponin (o). $n=5-8$ per genotype as indicated $* p<0.05, * * p<0.01, * * * p<0.001$

\section{Progressive liver fibrosis}

While inflammation and aggregation of foamy macrophages were the most obvious hepatic changes observed in tissue

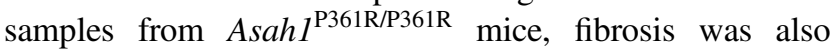
noted. This was assessed with soluble collagen measurement, Masson's trichrome staining, and reticulin staining conducted on liver tissue samples from $\mathrm{AsahI}^{+/+}$mice and Asahl $1^{\mathrm{P} 361 \mathrm{R} / \mathrm{P} 361 \mathrm{R}}$ mice (Fig. 4a-c). Trichrome staining demonstrated progressive fibrosis with age in samples from Asahl $1^{\mathrm{P} 361 \mathrm{R} / \mathrm{P} 361 \mathrm{R}}$ mice (Fig. S2A-D). To quantify fibrosis, soluble collagen was measured in liver tissue from Asahl ${ }^{+/+}$mice and Asahl ${ }^{\mathrm{P} 361 \mathrm{R} / \mathrm{P} 361 \mathrm{R}}$ mice. Asahl $1^{\mathrm{P} 361 \mathrm{R} / \mathrm{P} 361 \mathrm{R}}$ mouse livers displayed significantly increased collagen accumulation by 5 weeks of age compared to age-matched controls (Fig. 4a). While Asahl ${ }^{+/+}$control mouse livers displayed no further increase in collagen staining between 5 weeks of age and 9 weeks of age, $A s a h l^{\mathrm{P} 361 \mathrm{R} / \mathrm{P} 361 \mathrm{R}}$ mouse livers continued to accumulate collagen (Fig. 4a). In tissues from 9-week-old Asahl ${ }^{\mathrm{P} 361 \mathrm{R} / \mathrm{P} 361 \mathrm{R}}$ mice, there was significant periportal and periacinar accumulation of collagen and reticulin fibers (Fig. 4c, d), portal fibrosis (Fig. 4d), scarring in areas of histiocytic granulomas (Fig. 4e), and bridging fibrosis (Fig. 4f).

\section{Increased hepatocellular proliferation and death}

Histopathological analyses demonstrated mild necrosis and hepatocyte dropout (Table 1). To assess whether there was also increased cell proliferation and apoptotic cell death, IHC was conducted with antibodies for Ki67 and cleaved caspase-3 in liver sections from 3-week-old, 5week-old, 7-week-old, and 9-week-old $\mathrm{AsahI}^{+/+}$mice and Asahl ${ }^{\mathrm{P} 361 \mathrm{R} / \mathrm{P} 361 \mathrm{R}}$ mice (Fig. S3A-D). Asahl ${ }^{\mathrm{P} 361 \mathrm{R} / \mathrm{P} 361 \mathrm{R}}$ mice displayed an increase in Ki67 and cleaved caspase-3 nuclear labeling by 7 weeks of age (Fig. 5a, b). IHC for Ki67 in liver sections from 9-week-old $A s a h 1^{+/+}$mice demonstrated scattered periportal cellular proliferation (Fig. 5c). Asahl ${ }^{\mathrm{P} 361 \mathrm{R} / \mathrm{P} 361 \mathrm{R}}$ mouse livers displayed significantly more Ki67 labeling than controls at 9 weeks of age (Fig. 5d).

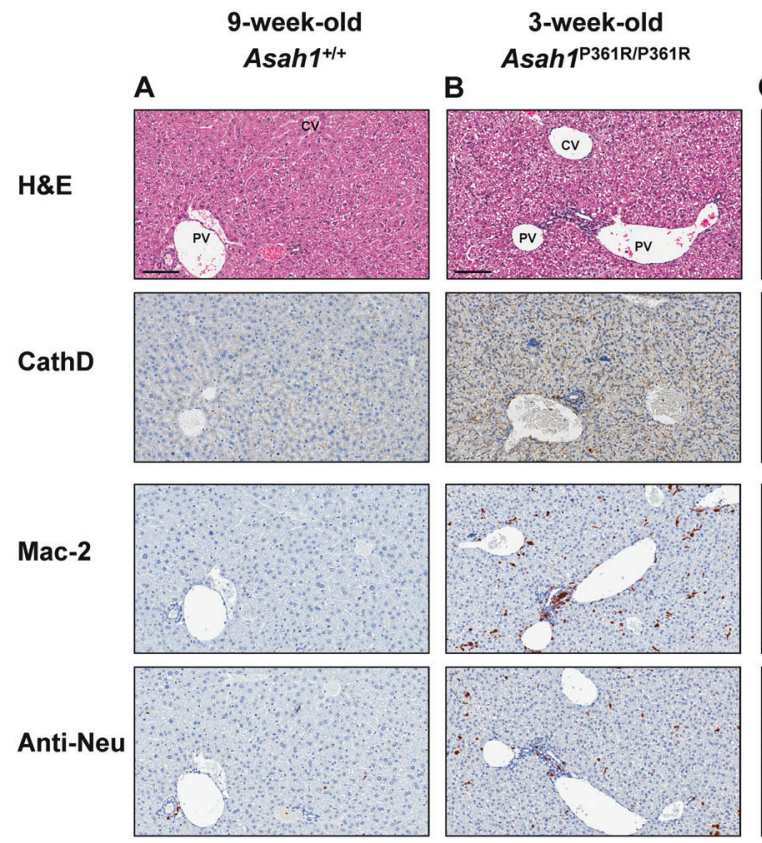

Fig. 2 Inflammation and pathology in the livers of Asah1 $1^{\mathrm{P} 361 \mathrm{R} / \mathrm{P} 361 \mathrm{R}}$ mice. Light micrographs of liver sections stained with hematoxylin and eosin (H\&E), and antibodies for cathepsin D (CathD), neutrophils (Anti-Neu), and macrophage (Mac-2) in Asah1 $1^{+/+}$mice and Asah1 $1^{\mathrm{P} 361 \mathrm{R} / \mathrm{P} 361 \mathrm{R}}$ mice. Micrographs of tissue from a 9-week-old

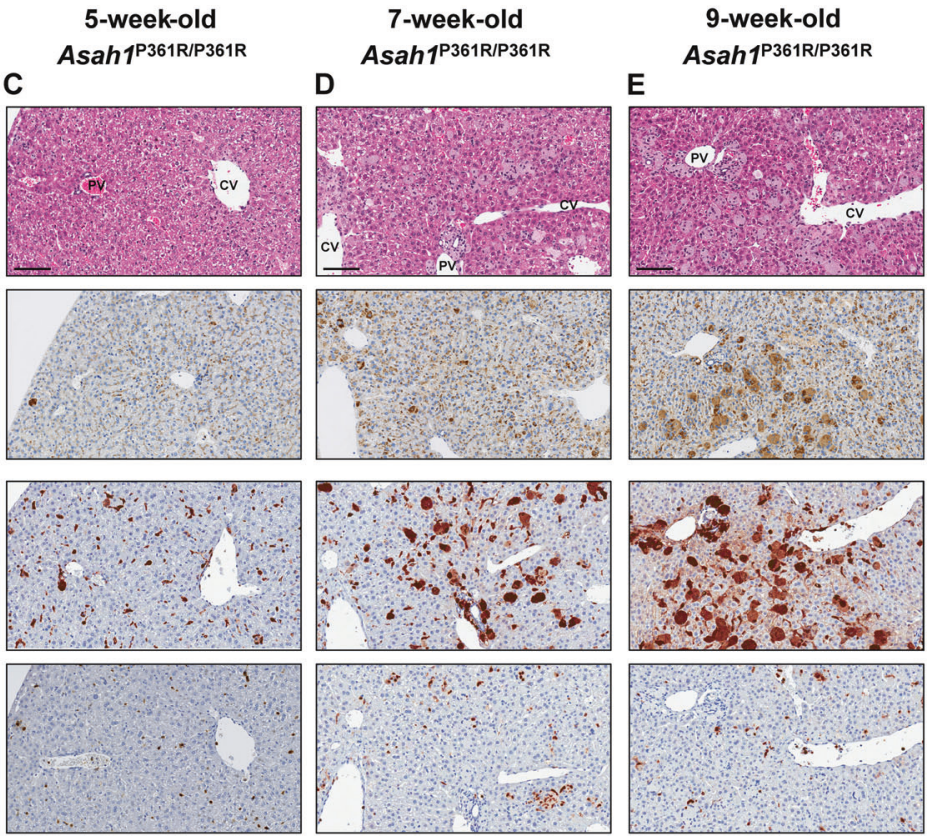

Asah1 $1^{+/+}$mouse with normal liver histology (a). Representative micrographs from 3-week-old, 5-week-old, 7-week-old, and 9-weekold $A s a h 1^{\mathrm{P} 361 \mathrm{R} / \mathrm{P} 361 \mathrm{R}}$ mice reveal progressive liver pathology (b-e). Annotations in figures: CV central vein, and PV portal vein. Scale bars for all micrographs indicate $100 \mu \mathrm{m}$ 

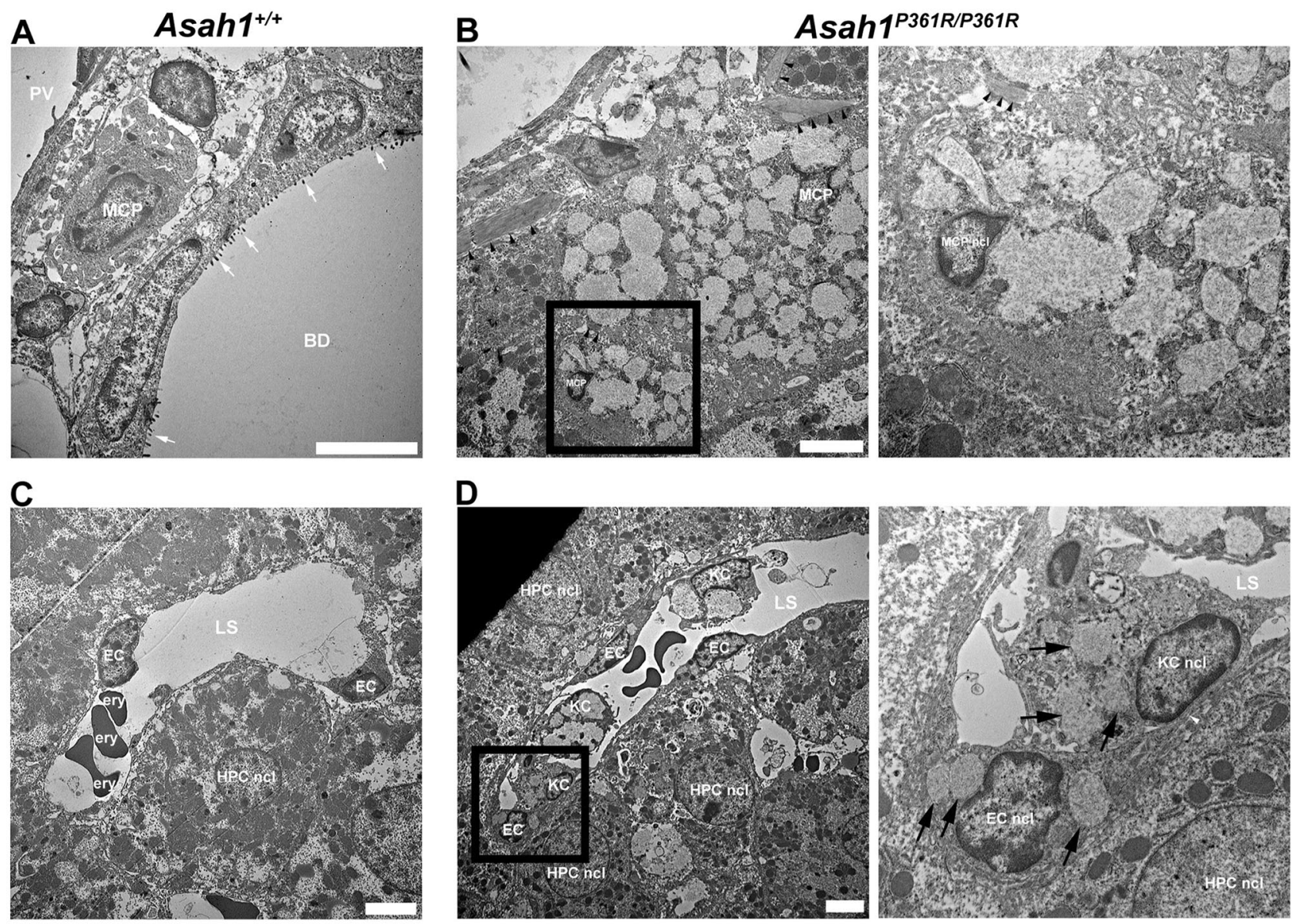

E

$\mathbf{F}$

G
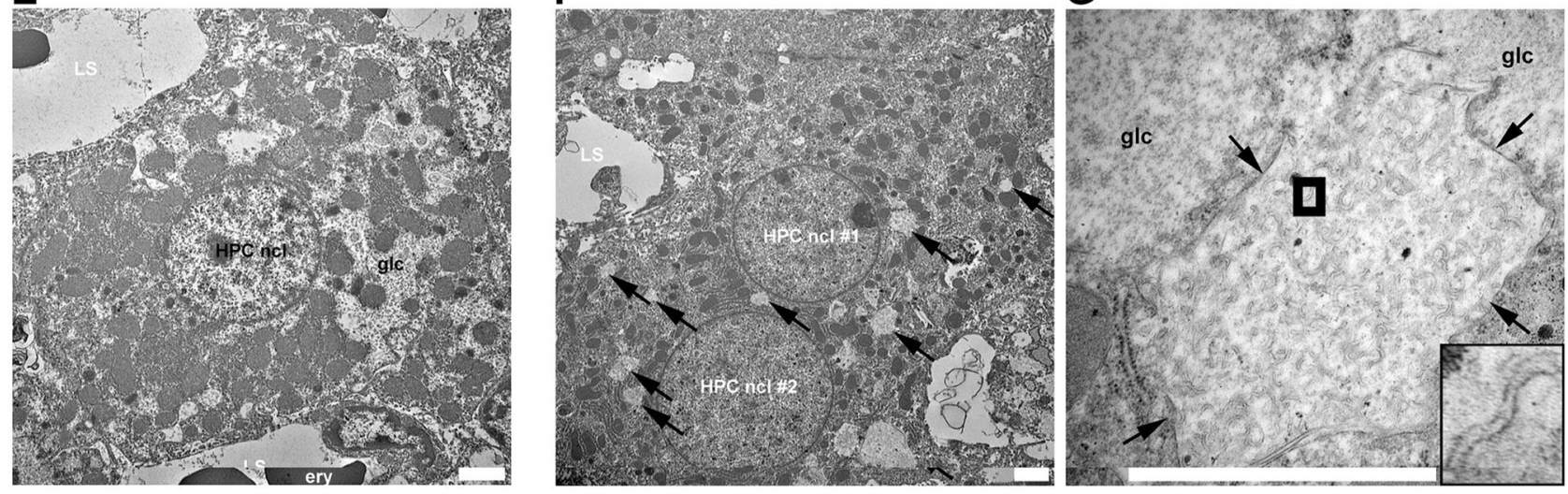

Fig. 3 Storage pathology within the portal fields and liver sinusoids in Asah1 ${ }^{\mathrm{P} 361 \mathrm{R} / \mathrm{P} 361 \mathrm{R}}$ mice. Electron micrograph of a representative portal field in samples from a 9-week-old Asah1 ${ }^{+/+}$mouse; white arrows highlight the lumen of a bile duct (a). Electron micrograph of a portal field in a 9-week-old Asahl $1^{\mathrm{P} 361 \mathrm{R} / \mathrm{P} 361 \mathrm{R}}$ mouse liver with excessive collagen fibers (black arrowheads) and infiltrating macrophages displaying cytoplasm containing excessive storage vacuoles with curvedlinear tubular profiles (CTB aka 'Farber bodies'). The rectangle corresponds to the adjacent magnified panel (b). Representative electron

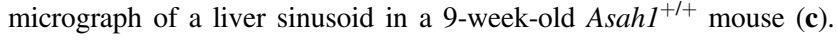
Electron micrograph of a liver sinusoid in a 9-week-old Asahl $1^{\mathrm{P} 361 \mathrm{R} / \mathrm{P} 361 \mathrm{R}}$ mouse featuring excessive storage vacuoles with CTB-like content in endothelial and Kupffer cells (black arrows in the magnified panel) (d). Electron micrograph of representative

hepatocytes from 9-week-old Asah1 ${ }^{+/+}$mice (e). Electron micrograph of tissues from a representative 9-week-old Asahl $1^{\mathrm{P} 361 \mathrm{R} / \mathrm{P} 361 \mathrm{R}}$ mouse featuring a bi-nucleated hepatocyte with membrane-bound storage vacuoles containing CTBs in the cytoplasm (black arrows) (f). High magnification of a membrane-bound storage vacuole (black arrows) in the cytoplasm of a hepatocyte. Higher magnification of a storage vacuole within a hepatocyte (g). The rectangle corresponds to internal panel featuring a single CTB. Annotations in the figure: BD bile duct lumen, EC endothelial cell, EC ncl nucleus of an endothelial cell, glc glycogen, HPC ncl nucleus of a hepatocyte, KC Kupffer cell, KC ncl nucleus of a Kupffer cell, LS liver sinusoid lumen, MCP macrophage, MCP ncl nucleus of a macrophage, PV portal vein lumen. Scale bars on micrographs indicate $2 \mu \mathrm{m}$ 
A

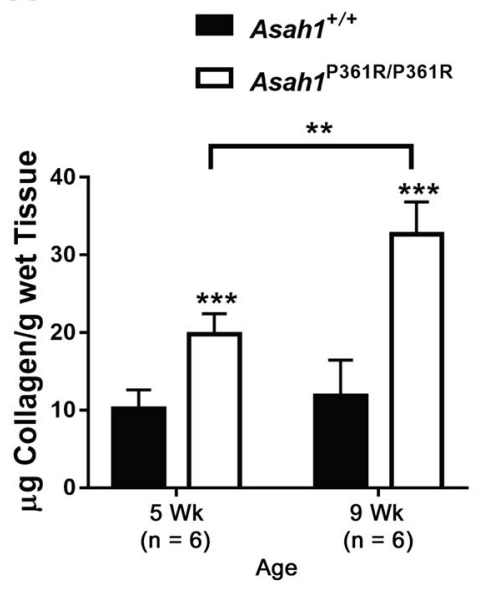

B
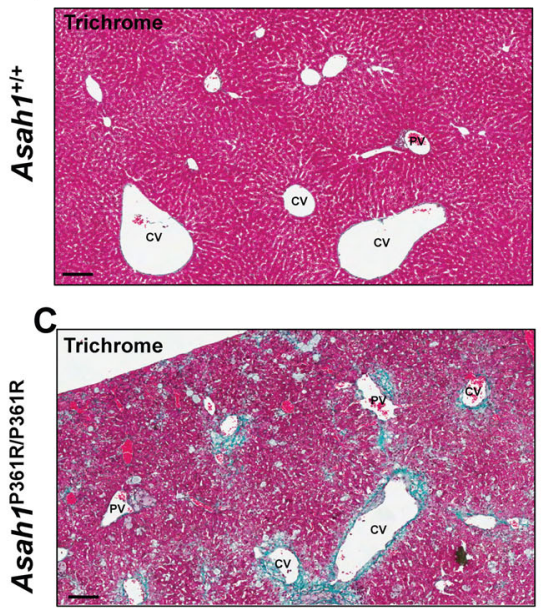

$\mathrm{E}$

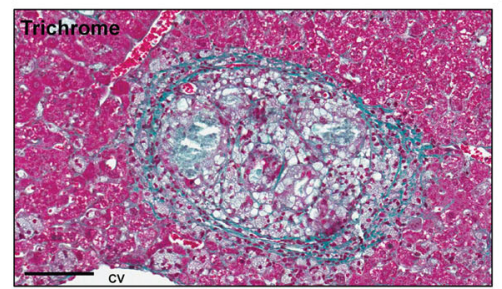

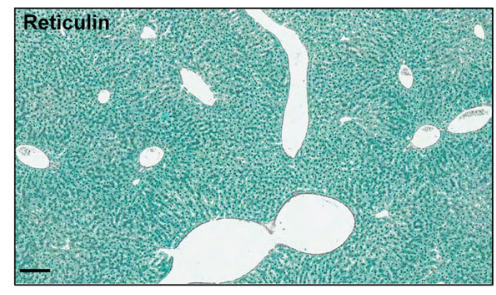

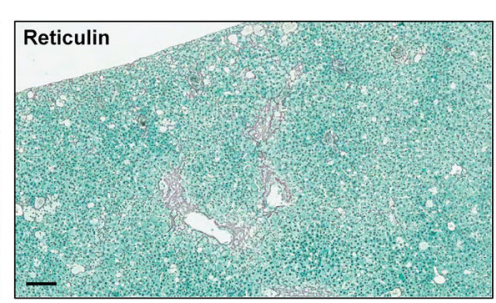

$\mathbf{F}$

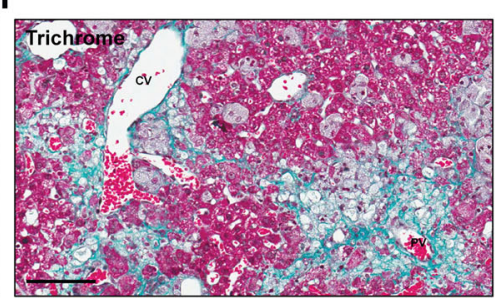

Fig. 4 Collagen accumulation and fibrosis in the liver of Asahl $1^{\mathrm{P} 361 \mathrm{R} / \mathrm{P} 361 \mathrm{R}}$ mice. Soluble collagen content was measured from the livers of 5-week-old and 9-week-old Asah1 $1^{+1+}$ mice and Asahl $1^{\mathrm{P} 361 \mathrm{R} / \mathrm{P} 361 \mathrm{R}}$ mice $(n=6$ mice per genotype) $* * * p<0.001$ (a). Representative light micrographs of 9 -week-old Asah1 $1^{+1+}$ mouse and Asahl ${ }^{\mathrm{P} 361 \mathrm{R} / \mathrm{P} 361 \mathrm{R}}$ mouse liver sections stained with Masson's trichrome and reticulin (b, c). Higher magnification micrograph of 9-week-old Asahl $1^{\mathrm{P} 361 \mathrm{R} / \mathrm{P} 361 \mathrm{R}}$ mouse liver sections stained for trichrome displaying fibrosis along the portal triad (d), extensive fibrosis within a histiocytic granuloma (e), and presence of central to portal bridging fibrosis (f). Annotations in figures: CV central vein, and PV portal vein. Scale bars for all micrographs indicate $100 \mu \mathrm{m}$

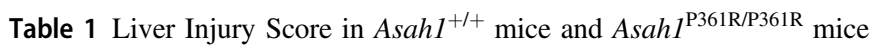

\begin{tabular}{|c|c|c|c|c|c|c|}
\hline & $\begin{array}{l}\text { Sample } \\
\text { size }\end{array}$ & $\begin{array}{l}\text { Histiocytic } \\
\text { abnormalities (0-4) }\end{array}$ & $\begin{array}{l}\text { Neutrophilic } \\
\text { infiltrates }(0-4)\end{array}$ & $\begin{array}{l}\text { Fibrosis } \\
(0-4)\end{array}$ & $\begin{array}{l}\text { Hepatocellular cytoplasmic } \\
\text { vacuolation }(0-4)\end{array}$ & Total Score \\
\hline Nine-week-old Asah1 $1^{+/+}$ & 5 & 0 & 0 & 0 & 0 & 0 \\
\hline Five-week-old Asahl $1^{\mathrm{P} 361 \mathrm{R} / \mathrm{P} 361 \mathrm{R}}$ & 5 & $2.6 \pm 0.6$ & $1.6 \pm 0.2$ & $1.8 \pm 0.4$ & $1.0 \pm 0.3$ & $7.0 \pm 1.2$ \\
\hline Nine-week-old Asah1 1 P361R/P361R & 5 & $3.6 \pm 0.2$ & $2.4 \pm 0.2$ & $3.0 \pm 0.3$ & $1.4 \pm 0.2$ & $10.4 \pm 0.5$ \\
\hline
\end{tabular}

Average liver injury score \pm SEM. Nine-week-old $A s a h 1^{+/+}$mice revealed no liver injury. Five-week-old and 9-week-old Asah1 ${ }^{\mathrm{P} 361 \mathrm{R} / \mathrm{P} 361 \mathrm{R}}$ mice show progressive liver injury

IHC labeling for Casp-3 and terminal deoxynucleotidyl transferase (dUTP) Nick-End Labeling (TUNEL) were muted in sections from Asahl ${ }^{+/+}$liver (Fig. 5e, g). In contrast, both Casp-3 and TUNEL labeling were present in hepatocytes from 9-week-old Asahl $1^{\mathrm{P} 361 \mathrm{R} / \mathrm{P} 361 \mathrm{R}}$ mice (Fig. 5f, h).

\section{Liver injury score}

To (semi)quantify the extent of liver injury in Asahl ${ }^{\mathrm{P} 361 \mathrm{R} /}$ P361R mice, a liver injury scoring system was developed. Significant liver injury was present by 5 weeks of age and increased in 9-week-old Asahl $1^{\mathrm{P} 361 \mathrm{R} / \mathrm{P} 361 \mathrm{R}}$ mice (Table 1).
Changes in Asahl $1^{\mathrm{P} 361 \mathrm{R} / \mathrm{P} 361 \mathrm{R}}$ mouse livers included increased accumulations of histiocytes, neutrophilic infiltrates and formation of granulomas, fibrosis, and hepatocellular cytoplasmic vacuolation, degeneration, and death (Table 1).

\section{Alteration to lipids in plasma and liver tissue}

Asahl $1^{\mathrm{P} 361 \mathrm{R} / \mathrm{P} 361 \mathrm{R}}$ mice lost weight (Fig. 1a) and displayed reduced fat pad sizes over time (data not shown). Serum biochemistry panels revealed a reduction in total cholesterol (Fig. 11). However, those analyses were not performed on fasted mice. Thus, we used LC-MS analysis to 
Fig. 5 Increased cell death and proliferation in the liver of Asahl ${ }^{\mathrm{P} 361 \mathrm{R} / \mathrm{P} 361 \mathrm{R}}$ mice.

Percentage of Ki67 (a) and cleaved capsase-3 (Casp-3) (b) positive cells quantified from tissue samples from 3-week-old, 5-week-old, 7-week-old, and 9week-old $A s a h 1^{+/+}$mice and Asah1 $1^{\mathrm{P} 361 \mathrm{R} / \mathrm{P} 361 \mathrm{R}}$ mice $(n=4$ mice per genotype).

Representative IHC staining for Ki67 in liver sections from 9week-old $A s a h 1^{+/+}$mice (c) and Asah1 $^{\mathrm{P} 361 \mathrm{R} / \mathrm{P} 361 \mathrm{R}}$ mice (d). Proliferating cells were noted within the periportal hepatic lobules (black arrowheads)

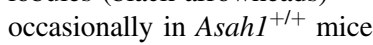
but more frequently in Asah1 $1^{\mathrm{P} 361 \mathrm{R} / \mathrm{P} 361 \mathrm{R}}$ mice.

Ki67 staining in hepatocytes of Asah1 $1^{\mathrm{P} 361 \mathrm{R} / \mathrm{P} 361 \mathrm{R}}$ mice (white arrowheads). Representative IHC staining for Casp-3 and terminal deoxynucleotidyl transferase (TdT) dUTP NickEnd Labeling (TUNEL) on 9week-old liver samples from $A \operatorname{sah} 1^{+/+}$mice $(\mathbf{e}, \mathbf{g})$ and Asahl $1^{\mathrm{P} 361 \mathrm{R} / \mathrm{P} 361 \mathrm{R}}$ mice $(\mathbf{g}, \mathbf{h})$. Cell death was noted within hepatocytes (black arrows) and invading inflammatory cells (white arrows). Annotations in figures: CV central vein, and PV portal vein. Scale bars for all micrographs indicate $100 \mu \mathrm{m}$
A
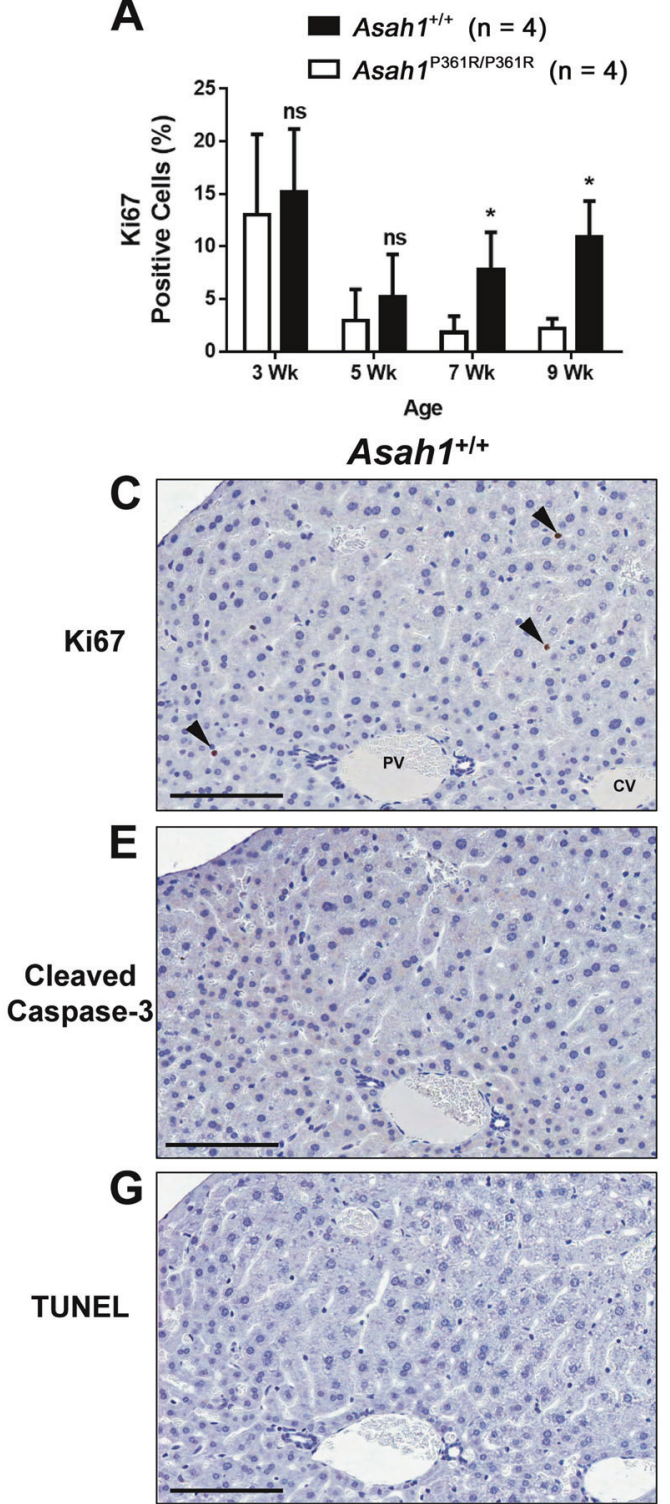

B

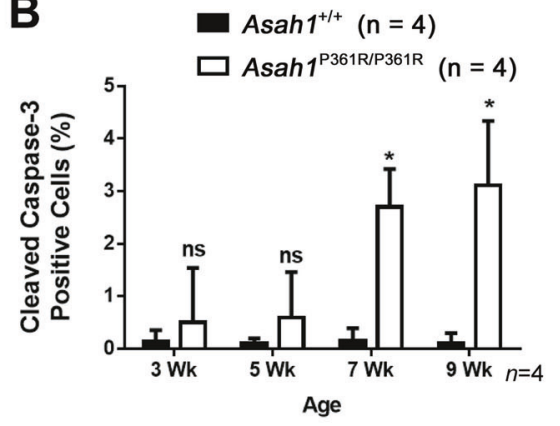

Asah1 19361R/P361R

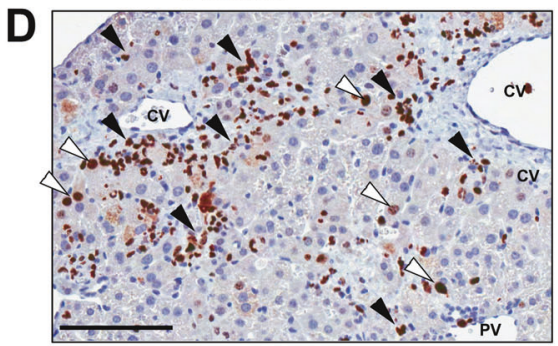

F
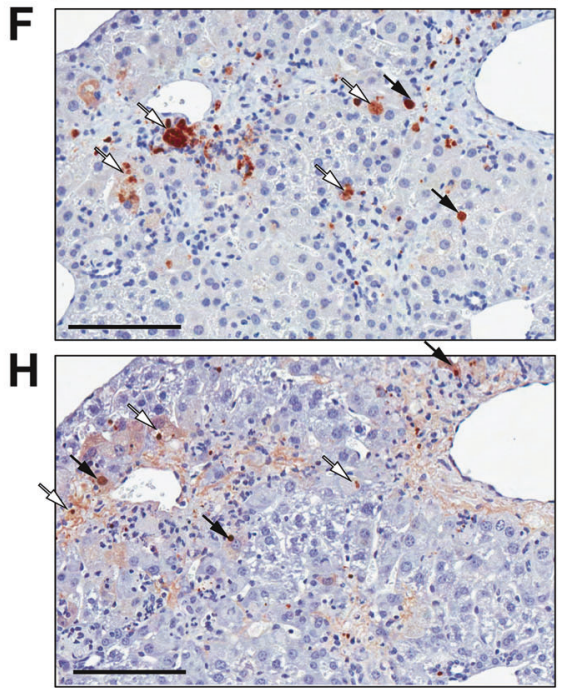

quantify free fatty acids (FFA), triglycerides (TG), phosphatidylcholine (PC), free cholesterol (FC), and total cholesterol (TC) both in liver lysates (Fig. 6a-e) and serum (Fig. 6f-j) from 8-9-week-old Asah1 ${ }^{+/+}$mice and Asahl $1^{\mathrm{P} 361 \mathrm{R} / \mathrm{P} 361 \mathrm{R}}$ mice that had been fasted overnight. Asahl P361R/P361R mice demonstrated significantly decreased FFA and TG in both liver tissue and serum (Fig. 6a, b, f, g). PC, FC, and TC were found to be significantly decreased in the serum, but not changed in liver lysates from Asahl ${ }^{\mathrm{P} 361 \mathrm{R} / \mathrm{P} 361 \mathrm{R}}$ mice (Fig. 6c-e, h-j).

\section{Altered sphingolipid profile in the liver}

Sphingolipids were quantified in liver lysates from 8-9week-old $\mathrm{Asahl}^{+/+}$mice and Asahl ${ }^{\mathrm{P} 361 \mathrm{R} / \mathrm{P} 361 \mathrm{R}}$ mice by LCMS. Liver tissue from Asahl $1^{\mathrm{P} 361 \mathrm{R} / \mathrm{P} 361 \mathrm{R}}$ mice displayed a significant increase in all species of ceramides including monohexosylceramides (MHC; including glucosylceramide and galactosylceramide) and derivatives such as ceramide1-phosphate (C1P) (Fig. 7a, d, e). While total sphingomyelin (SM) was significantly increased in liver lysates from Asahl ${ }^{\mathrm{P} 361 \mathrm{R} / \mathrm{P} 361 \mathrm{R}}$ mice, the greatest increase was seen in the SM16:0 and SM18:0 species (Fig. 7b). In contrast, no changes were seen in SM22:0 and SM24:0 species (Fig. 7b). Notably, the C16:0 and C18:0 species were also the most elevated in the ceramide and MHC analysis (Fig. 7a, d). Sphingosine (Sph) was significantly decreased in liver lysates from Asahl $1^{\mathrm{P} 361 \mathrm{R} / \mathrm{P} 361 \mathrm{R}}$ mice (Fig. 7c). When the relative abundance of each class of sphingolipids was calculated, an increase in 16:0 and 18:0 chain lengths was seen in each of ceramide, SM, and MHC, and 20:0 and 24:1 chain lengths were found elevated in ceramide, and MHC, 

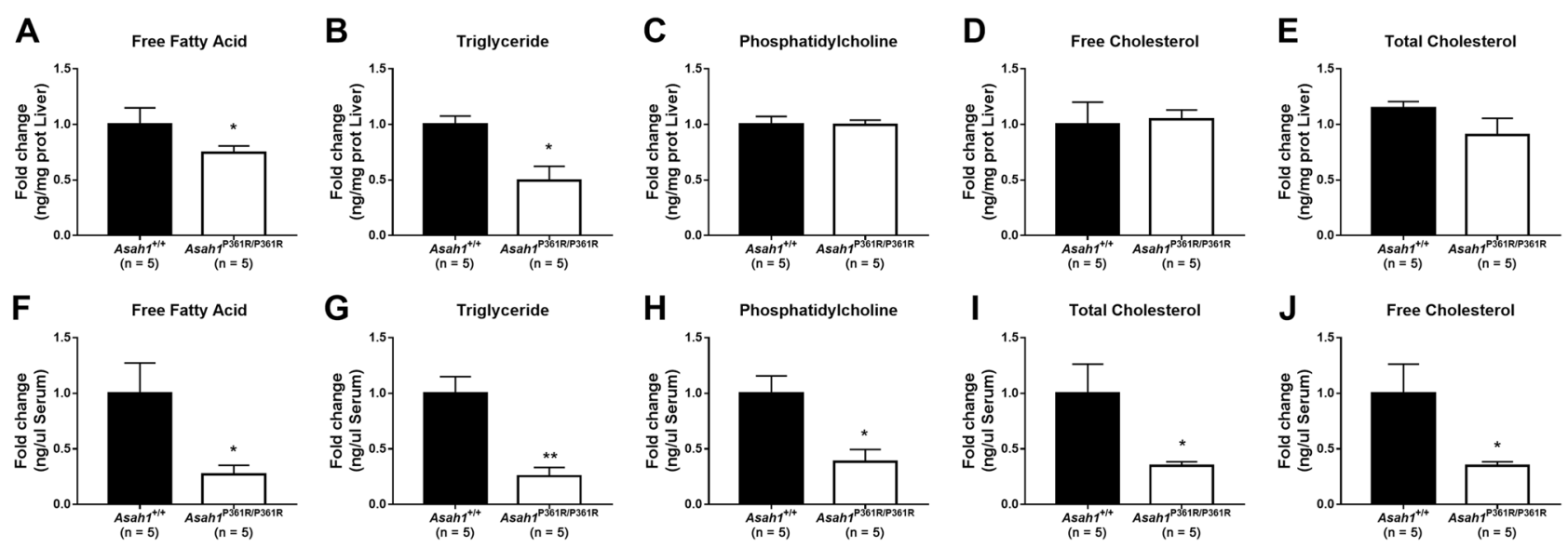

Fig. 6 Decreased lipids in serum and liver of Asahl ${ }^{\mathrm{P} 361 \mathrm{R} / \mathrm{P} 361 \mathrm{R}}$ mice. Free fatty acid (FFA) (a, f), triglyceride (TG) (b, g), phosphatidylcholine (PC) $(\mathbf{c}, \mathbf{h})$, free cholesterol (FC) $(\mathbf{d}, \mathbf{i})$, and total cholesterol
(TC) $(\mathbf{e}, \mathbf{j})$ measured in liver and plasma samples respectively from

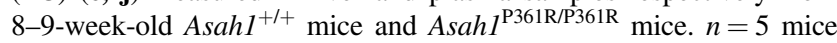
per genotype $* p<0.05, * * p<0.01$ but not SM from Asahl $1^{\mathrm{P} 361 \mathrm{R} / \mathrm{P} 361 \mathrm{R}}$ mouse liver lysates (Fig. 7f, h). 22:0 and 24:0 chain lengths were found decreased in ceramide, SM, and MHC, while 20:0 and 24:1 chain lengths were found decreased in SM from Asahl ${ }^{\mathrm{P} 361 \mathrm{R} / \mathrm{P} 361 \mathrm{R}}$ mouse liver lysates (Fig. 7f-h). The relative abundance of the C1P species measured (C22:0, C24:1, and

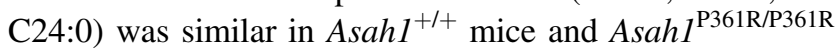
mice (Fig. 7i).

\section{Hepatocyte isolation and sphingolipid profile}

Lipidomic analyses were also conducted on hepatocyteenriched cultures. A 'two-step' collagenase liver perfusion method $[32,34]$ was used to isolate primary hepatocytes and reduce macrophage contamination from Asahl $1^{+/+}$ mouse and Asahl $1^{\mathrm{P} 361 \mathrm{R} / \mathrm{P} 361 \mathrm{R}}$ mouse livers. The 5-week timepoint was selected for evaluation as it represents the mid-point in $A s a h 1^{\mathrm{P} 361 \mathrm{R} / \mathrm{P} 361 \mathrm{R}}$ mouse lifespan and presents a milder inflammatory phenotype. Flow cytometry for CD11b (Macrophage-1 antigen) demonstrated a significant reduction in macrophages compared to non-hepatocyte-enriched liver tissue from 5-week-old Asahl P361R/P361R mice (Fig. S4).

Similar sphingolipid expression changes as those seen in liver tissue were observed by LC-MS conducted on these hepatocyte-enriched cultures. Hepatocyte-enriched cultures from $A s a h 1^{\mathrm{P} 361 \mathrm{R} / \mathrm{P} 361 \mathrm{R}}$ mice displayed significantly increased levels of total ceramide, SM, and MHC (Fig. 8a, c, e). The 16:0 and 18:0 chain length species showed the largest fold-changes for each of ceramide, SM, and MHC (Fig. 8a, c, e). C1P and Sph levels were below the limit of detection (data not shown). When the relative abundance of each class of sphingolipids was calculated, an increase in 16:0 and 18:0 chain lengths was seen in each of ceramide, SM, and MHC, and the 20:0 chain length was elevated in ceramide, and SM, but not MHC from Asahl $1^{\mathrm{P} 361 \mathrm{R} / \mathrm{P} 361 \mathrm{R}}$ mouse hepatocyte-enriched cultures (Fig. 8b, d, f). 22:0, 24:1, and 24:0 chain lengths were found decreased in ceramide, SM, and MHC, while the 20:0 chain length was decreased in MHC from Asahl $P^{\mathrm{P} 361 \mathrm{R} / \mathrm{P} 361 \mathrm{R}}$ mouse hepatocyte-enriched cultures (Fig. 8b, d, f).

\section{Differential gene expression in hepatocytes}

RNAseq analyses were conducted on hepatocyte-enriched cultures derived from 5-week-old $\mathrm{AsahI}^{+/+}$mice and Asahl ${ }^{\mathrm{P} 361 \mathrm{R} / \mathrm{P} 361 \mathrm{R}}$ mice. Across all cDNA libraries we found high transcript yields $\left(2.96 \pm 3 \times 10^{-3} \mathrm{~Gb}\right)$, read numbers $(24.2 \pm 0.02$ million/library), and mapping rates $(88.8 \pm$ $0.13 \%$ ) (Table S2). Substantial differences in the transcriptomes were detected between samples from $\mathrm{Asahl}^{+/+}$ mice and Asahl $1^{\mathrm{P} 361 \mathrm{R} / \mathrm{P} 361 \mathrm{R}}$ mice. The complete RNAseq dataset is provided in Table S3.

\section{Perturbed sphingolipid homeostasis}

To gain insight into the molecular pathway changes in ACDase deficiency, all gene transcripts found differentially expressed in hepatocyte-enriched cultures from Asah1 $1^{+/+}$ mice and $A s a h l^{\mathrm{P} 361 \mathrm{R} / \mathrm{P} 361 \mathrm{R}}$ mice were further analyzed using Ingenuity Pathway Analysis (IPA) software. The 2000 gene transcripts identified to be most up or downregulated in Asahl ${ }^{\mathrm{P} 361 \mathrm{R} / \mathrm{P} 361 \mathrm{R}}$ mice are presented as a heat map in Fig. S5. Of these gene transcripts, the most significantly altered play roles in cellular lipid metabolism (146 gene transcripts, $p$-value range $\left.8.54 \times 10^{-7}-7.42 \times 10^{-39}\right)$, molecular transport (164 gene transcripts, $p$-value $9.54 \times$ $\left.10^{-7}-4.38 \times 10^{-27}\right)$, the inflammatory response (168 gene transcripts, $p$-value $\left.8.22 \times 10^{-7}-2.84 \times 10^{-26}\right)$, cellular function and maintenance (152 gene transcripts, $p$-value 

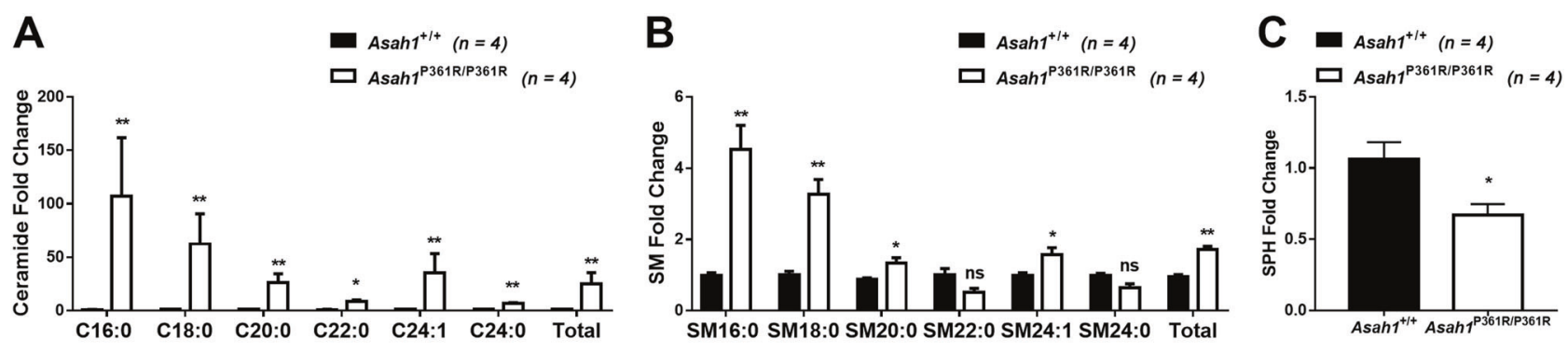

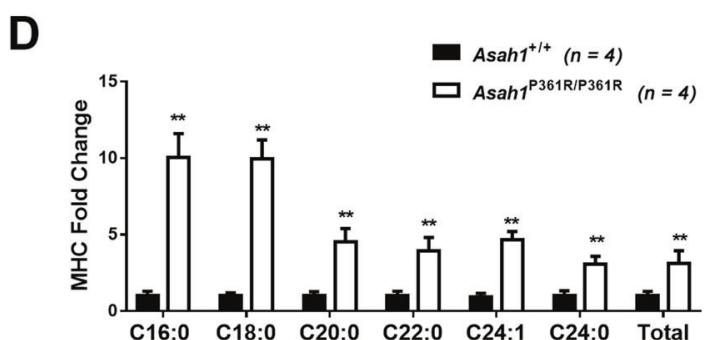

$\mathbf{F}$

\section{Relative abundance of Ceramide}
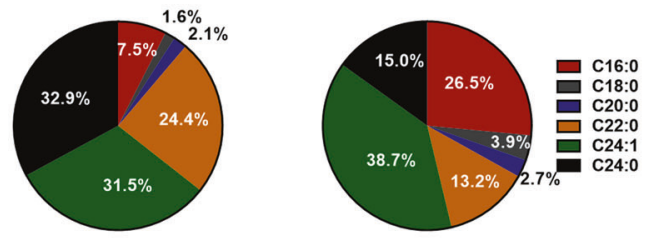

Asah1 $^{+/+}$

Asah1 $^{\mathrm{P} 361 \mathrm{R} / \mathrm{P} 361 \mathrm{R}}$

H

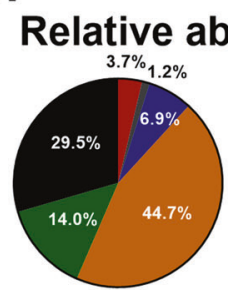

Asah1 $^{+/+}$

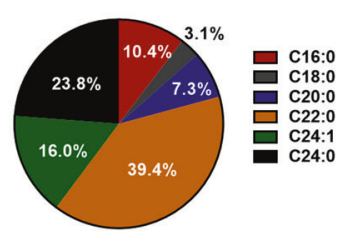

Asah1 $^{\mathrm{P} 361 \mathrm{R} / \mathrm{P} 361 \mathrm{R}}$
Fig. 7 Sphingolipid accumulation in the livers of Asahl $1^{\mathrm{P} 361 \mathrm{R} / \mathrm{P} 361 \mathrm{R}}$ mice. Quantification of ceramide species in liver lysates from Asahl $^{+/+}$mice and Asahl P361R/P361R $^{\text {mice (a). Quantification of }}$ sphingomyelin (SM) species in liver lysates from Asah1 ${ }^{+/+}$mice and Asah1 $1^{\mathrm{P} 361 \mathrm{R} / \mathrm{P} 361 \mathrm{R}}$ mice (b). Quantification of sphingosine (Sph) in liver lysates from $A s a h 1^{+/+}$mice and $A s a h 1^{\mathrm{P} 361 \mathrm{R} / \mathrm{P} 361 \mathrm{R}}$ mice (c). Quantification of monohexosylceramide (MHC) species in liver lysates from Asah1 $1^{+/+}$mice and Asahl $1^{\mathrm{P} 361 \mathrm{R} / \mathrm{P} 361 \mathrm{R}}$ mice (d). Quantification of ceramide-1-phosphate (C1P) species in liver lysates from Asah1 $1^{+/+}$

$\left.8.09 \times 10^{-7}-2.84 \times 10^{-26}\right)$, and immune cell trafficking (102 gene transcripts, $p$-value $\left.9.54 \times 10^{-7}-7.40 \times 10^{-26}\right)$. We were most interested in the dysregulated genes involved in cellular lipid metabolism. Cluster analysis revealed many significant genes in this pathway to be dysregulated in the hepatocyte-enriched cultures from Asahl $I^{\mathrm{P} 361 \mathrm{R} / \mathrm{P} 361 \mathrm{R}}$ mice (Fig. 9a).

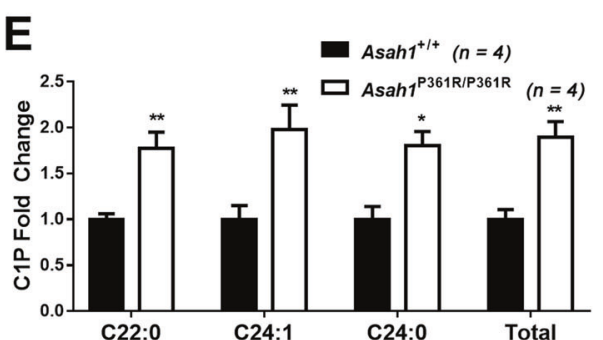

G

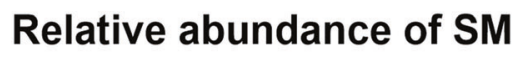

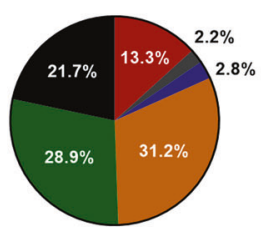

Asah1 $^{+/+}$

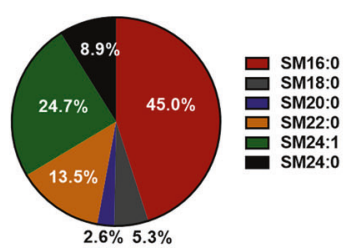

Asah1 $^{\mathrm{P} 361 \mathrm{R} / \mathrm{P} 361 \mathrm{R}}$

\section{I}

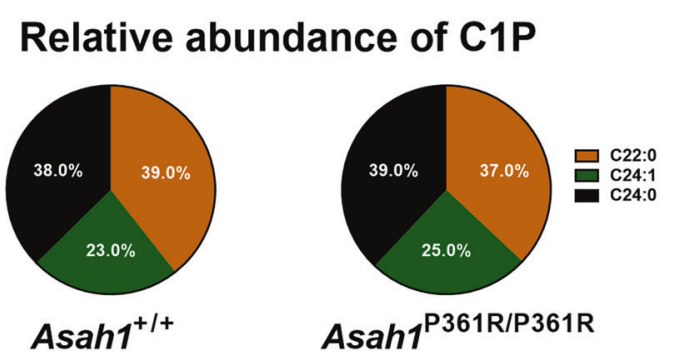

mice and $A s a h 1^{\mathrm{P} 361 \mathrm{R} / \mathrm{P} 361 \mathrm{R}}$ mice (e). Relative abundance of ceramide

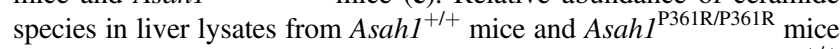
(f). Relative abundance of SM species in liver lysates from Asah1 ${ }^{+/+}$ mice and Asahl $1^{\mathrm{P} 361 \mathrm{R} / \mathrm{P} 361 \mathrm{R}}$ mice (g). Relative abundance of MHC species in liver lysates from $A s a h 1^{+/+}$mice and $A s a h 1^{\mathrm{P} 361 \mathrm{R} / \mathrm{P} 361 \mathrm{R}}$ mice (h). Relative abundance of C1P species in liver lysates from Asah1 $1^{+/+}$ mice and $A s a h 1^{\mathrm{P} 361 \mathrm{R} / \mathrm{P} 361 \mathrm{R}}$ mice (i). Liver lysates were obtained from 8-9-week-old $A s a h 1^{+/+}$mice and Asahl ${ }^{\mathrm{P} 361 \mathrm{R} / \mathrm{P} 361 \mathrm{R}}$ mice. $n=4$ mice per genotype. $* p<0.05 * * p<0.01, * * * p<0.001$

We validated the RNAseq analysis by conducting realtime PCR measurements on several of the upregulated and downregulated gene transcripts in this pathway in hepatocyte-enriched cultures obtained from a separate cohort of mice (Fig. 9b-g). Ceramide kinase (CerK), a gene that encodes for the enzyme that converts ceramide to C1P, was found by RNAseq analysis (z-score from -0.89 to 


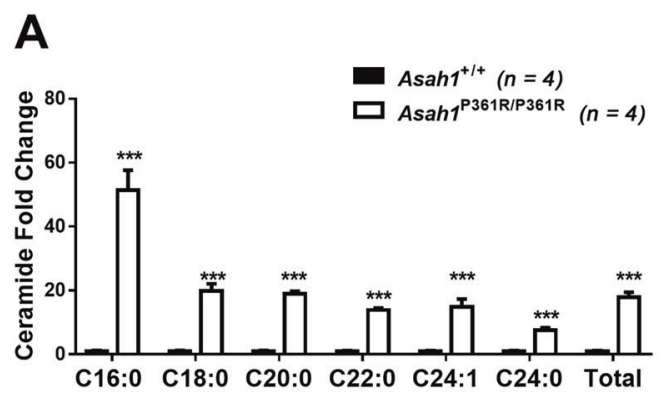

B
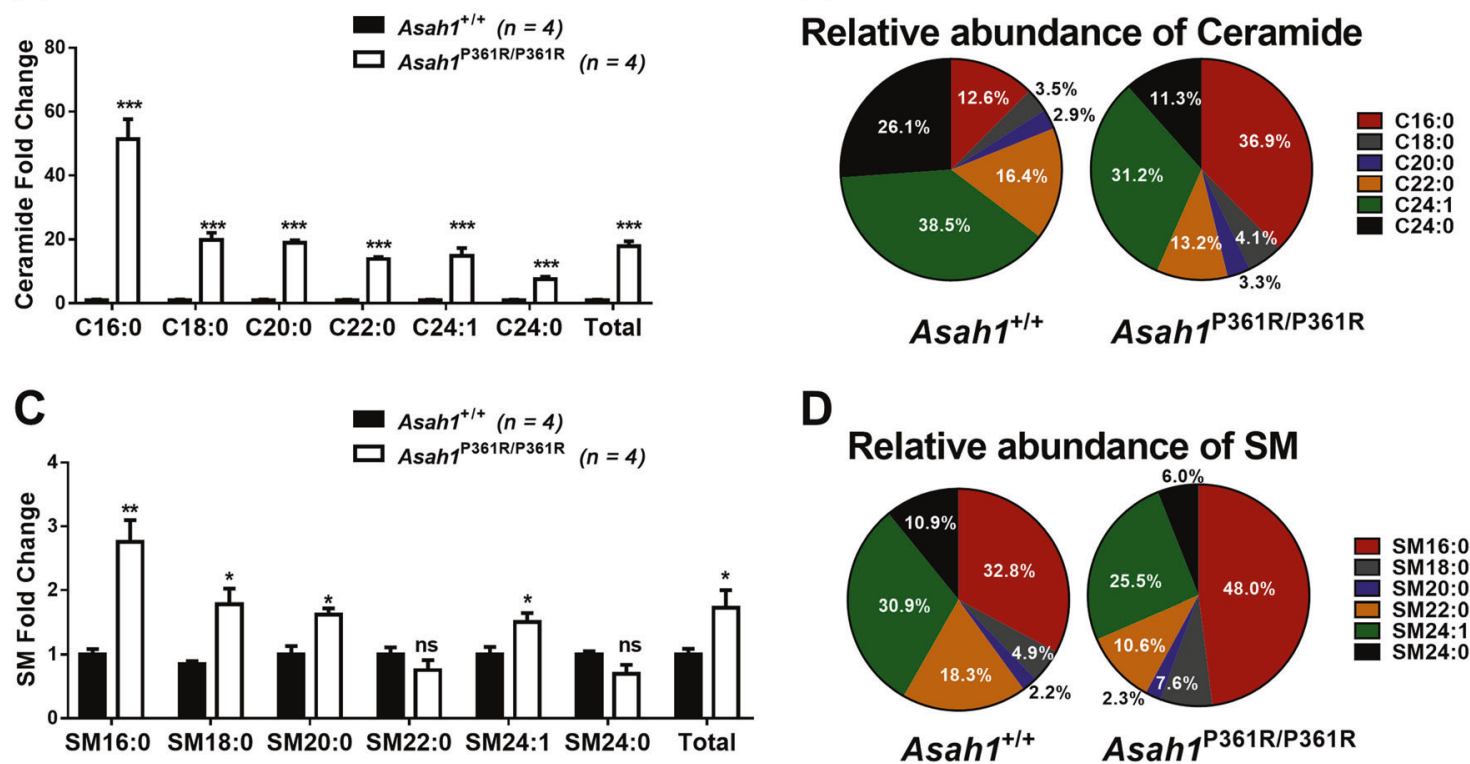

D
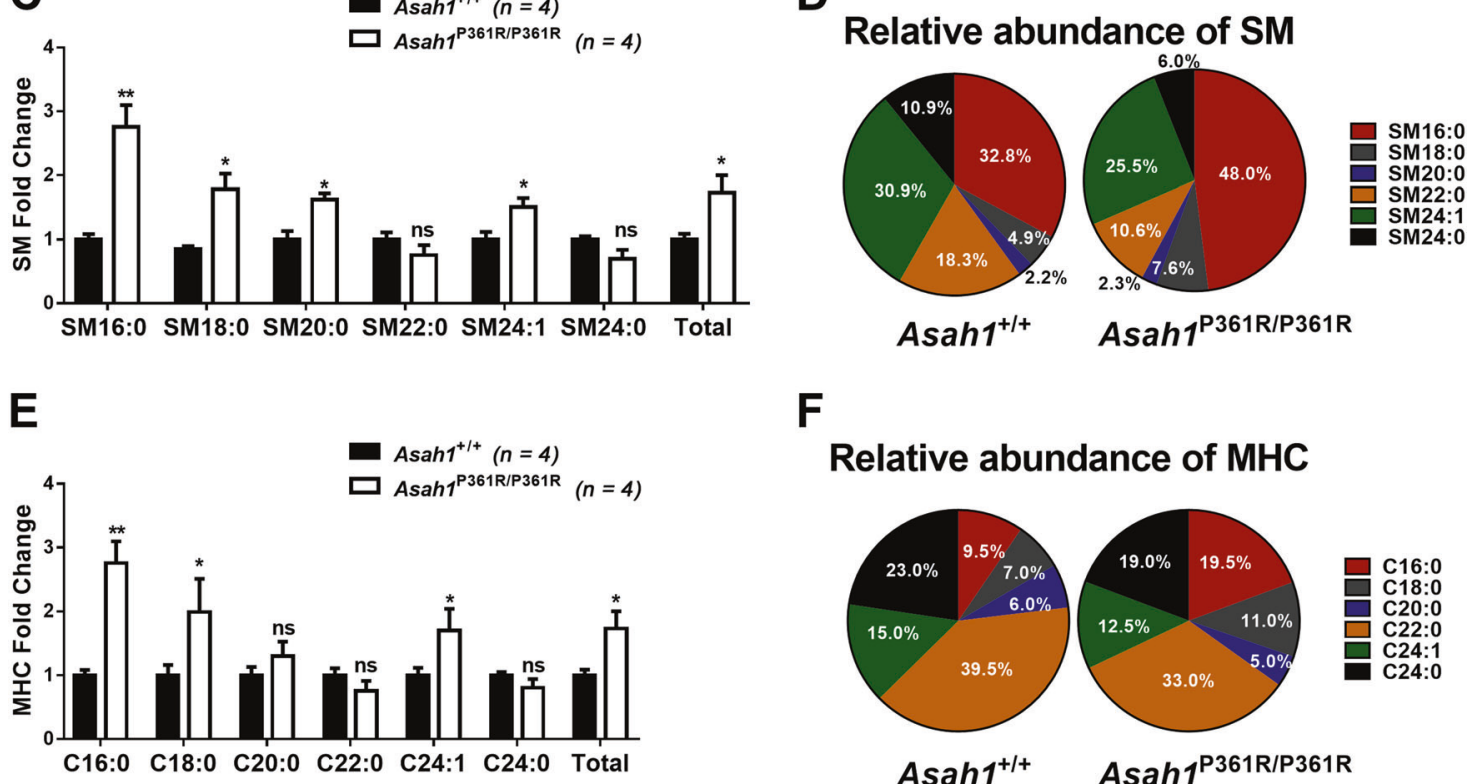

Fig. 8 Sphingolipid accumulation in hepatocytes from Asahl $1^{\mathrm{P} 361 \mathrm{R} / \mathrm{P} 361 \mathrm{R}}$ mice. Quantification (a) and relative abundance (b) of ceramide species in hepatocyte-enriched cultures from $A s a h 1^{+/+}$mice and Asahl ${ }^{\mathrm{P} 361 \mathrm{R} / \mathrm{P} 361 \mathrm{R}}$ mice. Quantification (c) and relative abundance (d) of SM species in hepatocyte-enriched cultures from Asah1 $1^{+/+}$mice and Asahl ${ }^{\mathrm{P} 361 \mathrm{R} / \mathrm{P} 361 \mathrm{R}}$ mice. Quantification (e) and relative abundance

0.89) and real-time PCR to be significantly upregulated (Fig. 9a, b). Psap, which encodes for a glycoprotein that generates four different polypeptides known as saposins A, $\mathrm{B}, \mathrm{C}$, and $\mathrm{D}$, was also found upregulated by RNAseq ( $\mathrm{z}-$ score from -0.90 to 0.90 ) and real-time PCR (Fig. 9a, c). The four saposins act as activators of lysosomal hydrolases for sphingolipid catabolism. Additionally, we observed significant upregulation in ceramide glucosyltransferase $(U g c g)$, a gene that is involved in the production of glucocerebrosides, by RNAseq analysis (z-score from -0.63 to 0.63 ) and real-time PCR (Fig. 9a, d).

Several downregulated gene transcripts were also validated, including ceramide synthase 2 (Cers2) and Cers 4 (Fig. 9a). Ceramide synthases are proteins that catalyze the synthesis of ceramide. Cers2 is the enzyme that primarily synthesizes very long acyl chain ceramides (C22-24) while Cers4 primarily synthesizes $\mathrm{C} 18-\mathrm{C} 22$. Both Cers 2 and
Cers 4 were found downregulated by RNAseq (Cers 2 z-score from -0.64 to 0.64 , Cers 4 z-score from -0.87 to 0.87 ) and validated by real-time PCR (Fig. 9e, f). Additionally, diacylglycerol acyltransferase 2 (Dgat2), a gene that encodes for an enzyme that catalyzes triglyceride and acyl ceramide generation, was also found downregulated by RNAseq (z-score from -0.89 to 0.89 ) and real-time PCR analysis (Fig. 9a, g).

\section{Inflammatory response and lipid homeostasis pathways}

IPA software analyses revealed that while many pathways displayed gene transcript expression changes, only a few pathways were significantly activated (the combined result of all gene transcript expression changes predicts pathway activation) or deactivated (the combined result of all gene 
A

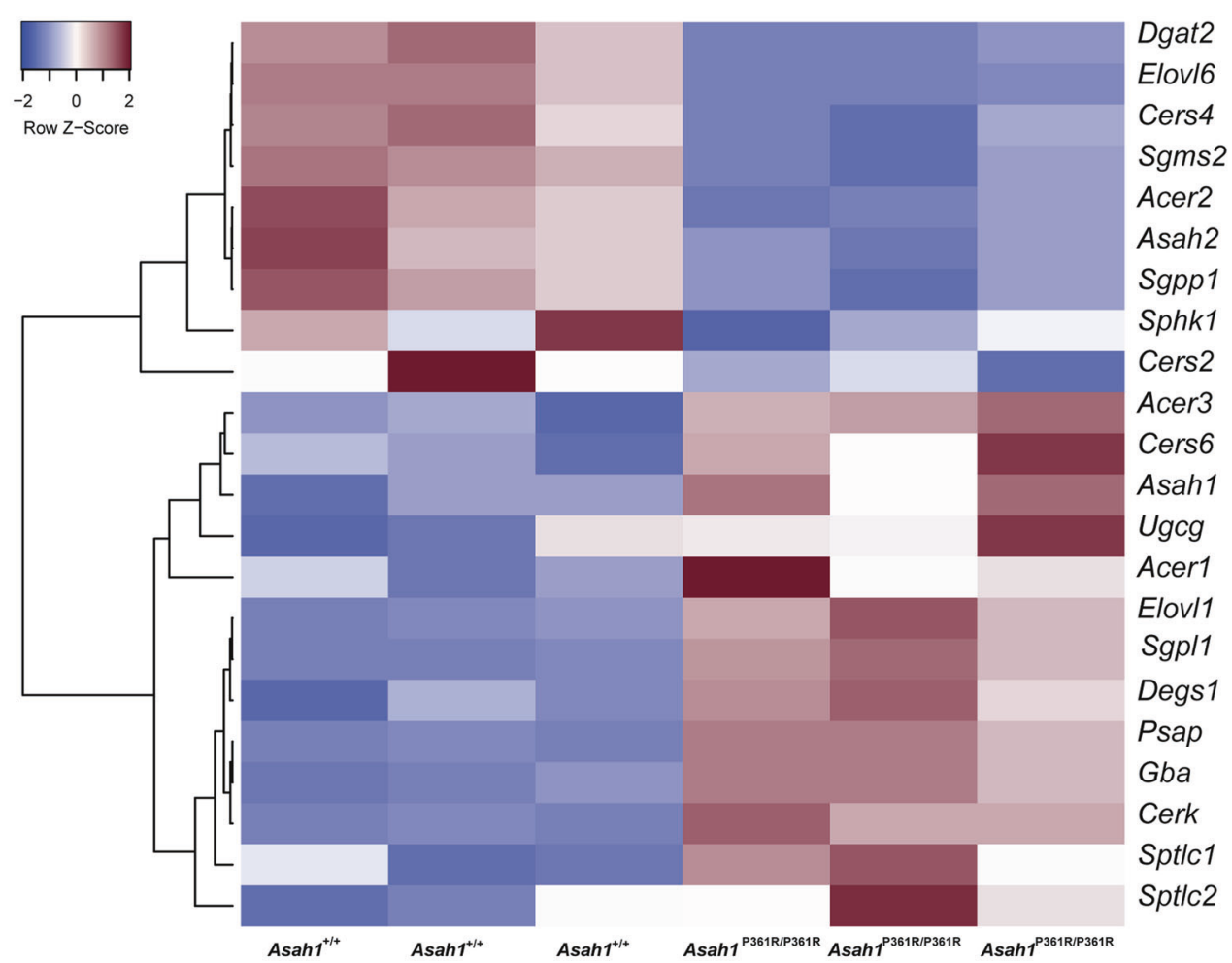

Asah1 $^{+/+}$

$\square$ Asah1 $^{\mathrm{P} 361 \mathrm{R} / \mathrm{P} 361 \mathrm{R}}$

B

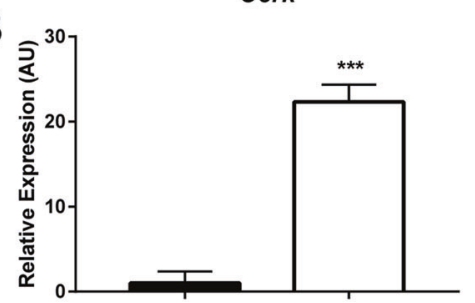

E

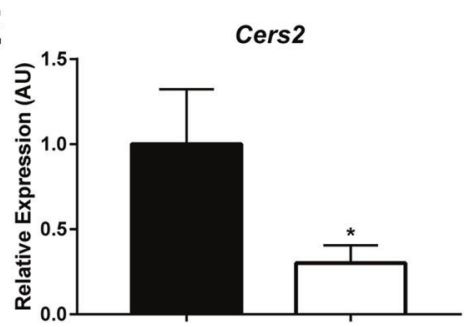

C

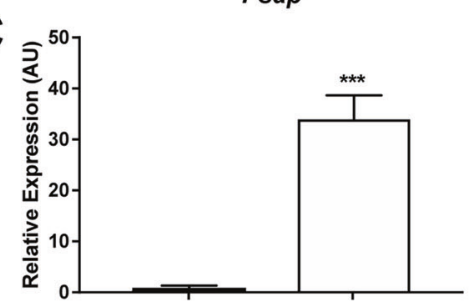

$\mathbf{F}$

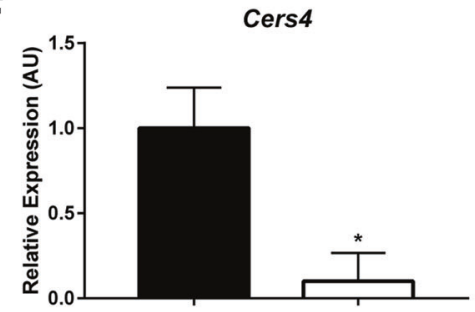

D

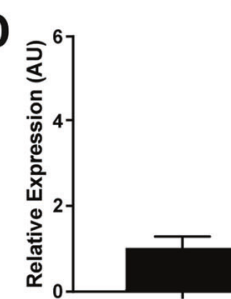

G

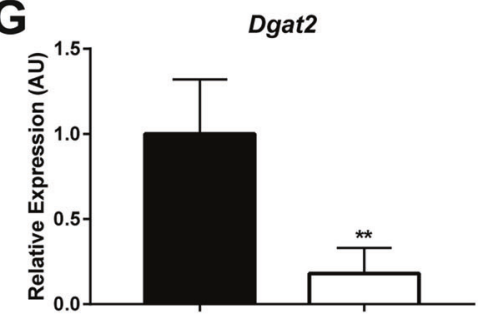

Fig. 9 Altered expression of gene transcripts involved in sphingolipid metabolism in Asah1 $1^{\mathrm{P} 361 \mathrm{R} / \mathrm{P} 361 \mathrm{R}}$ mice. Hierarchical clustering of significantly altered transcripts of genes involved in the sphingolipid metabolism pathway analyzed in samples from $3 \mathrm{Asahl}^{+/+}$mice (left) and 3 Asahl $^{\mathrm{P} 361 \mathrm{R} / \mathrm{P} 361 \mathrm{R}}$ (right) mice (a). Gene transcripts induced are depicted in red, gene transcripts repressed are depicted in blue. RealTime PCR analyses confirmed altered regulation of sphingolipid

transcript expression changes predicts pathway deactivation). The most significantly activated pathway in Asah1 $1^{\text {P361R/P361R }}$ mouse hepatocytes was the leukocyte extravasation signaling pathway (z-score $=3.61 ; 15$ of 211 metabolism pathway members ceramide kinase (Cerk) (b), prosaposin $(P$ sap $)(\mathbf{c})$, ceramide glucosyltransferase $(\mathrm{Ugcg})(\mathbf{d})$, ceramide synthase 2 (Cers2) (e), ceramide synthase 4 (Cers4) (f), and diacylglycerol o-acyltransferase 2 (Dgat2) (g) in tissue samples from a different cohort of 4 Asahl $^{+/+}$mice and 4 Asahl $1^{\mathrm{P} 361 \mathrm{R} / \mathrm{P} 361 \mathrm{R}}$ mice. $* p<$ $0.05 * * p<0.01, * * * p<0.001$

genes significantly modified, $p$-value $=3.91 \times 10^{-6}$ ). Cluster analysis of genes within this pathway revealed significant differences between the transcriptomes of hepatocyte-enriched cultures from 5-week-old Asah1 $1^{+/+}$ 
A

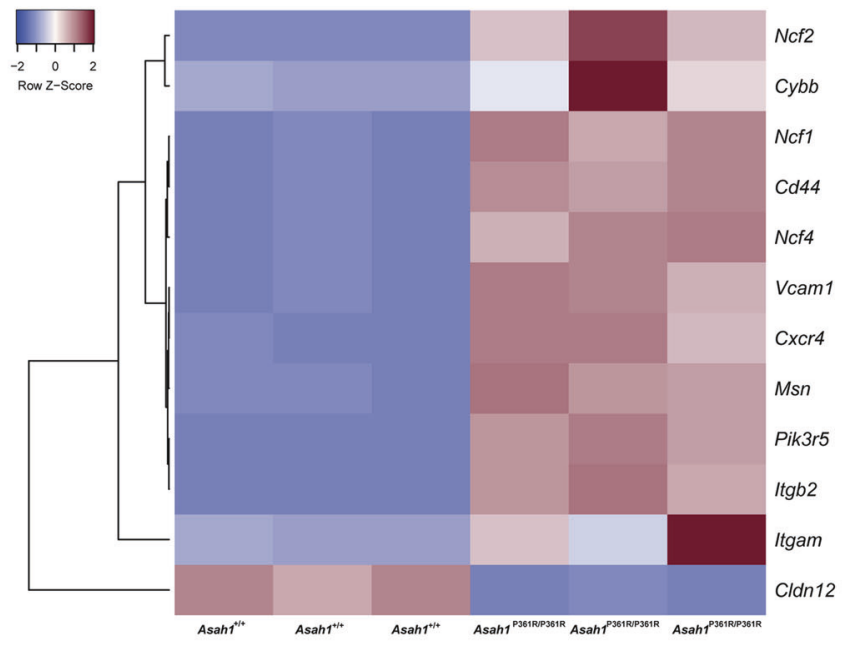

B

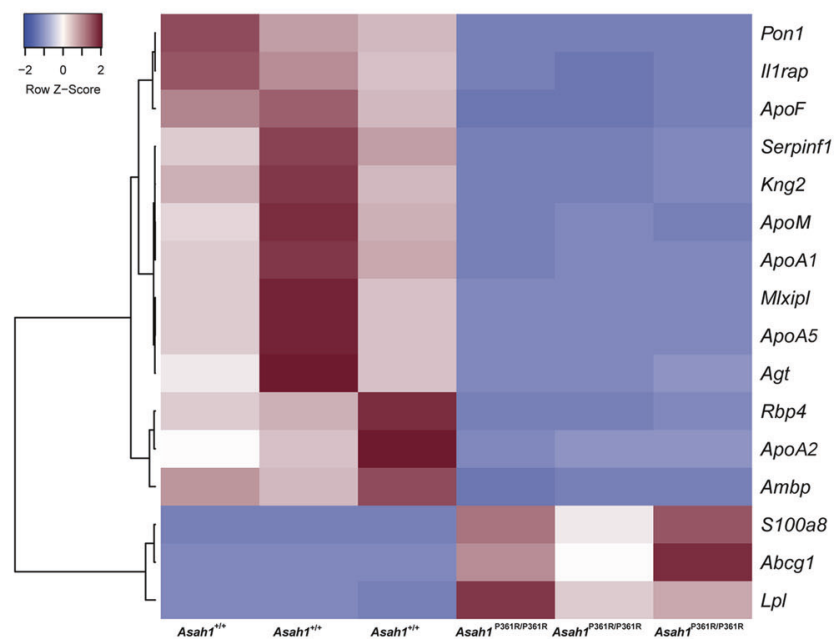

C

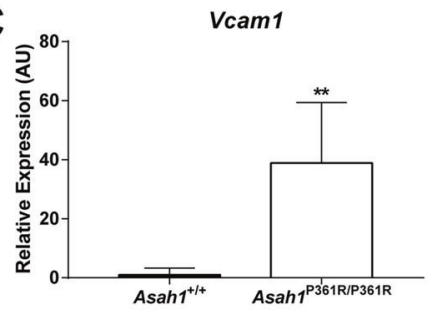

D

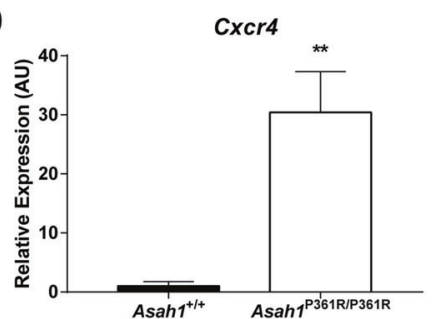

E

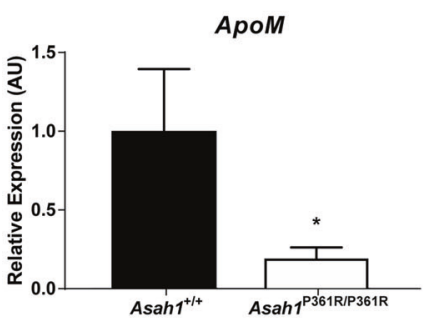

$\mathbf{F}$

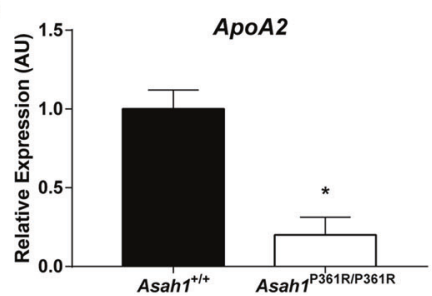

Fig. 10 Altered expression of gene transcripts involved in leukocyte extravasation signaling and LXR/RXR activation pathways in Asah1 $1^{\mathrm{P} 361 \mathrm{R} / \mathrm{P} 361 \mathrm{R}}$ mice. Hierarchical clustering of significantly altered transcripts of genes involved in the leukocyte extravasation signaling (a) and LXR/RXR activation (b) pathways in samples from 3

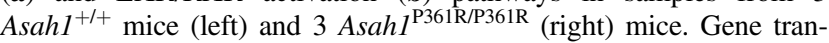
scripts induced are depicted in red, gene transcripts repressed are depicted in blue. Real-Time PCR analyses confirmed leukocyte extravasation signaling pathway member vascular cellular adhesion molecule 1 (Vcam1) (c), and chemokine (C-X-C motif) receptor 4 $(\mathrm{Cxcr} 4)$ (d) upregulation in a different cohort of $4 \mathrm{Asahl}^{+/+}$mice and 4 Asahl $^{\mathrm{P} 361 \mathrm{R} / \mathrm{P} 361 \mathrm{R}}$ mice. Real-Time PCR analyses confirmed LXR/ RXR activation pathway member Apolipoprotein M (ApoM) (e), and Apolipoprotein A2 (ApoA2) (f) downregulation in tissues from a different cohort of $4 A s a h 1^{+/+}$mice and $4 A \operatorname{sahl} 1^{\mathrm{P} 361 \mathrm{R} / \mathrm{P} 361 \mathrm{R}}$ mice. ${ }^{*} p<$ $0.05, * * p<0.01$ mice and Asahl $1^{\mathrm{P} 361 \mathrm{R} / \mathrm{P} 361 \mathrm{R}}$ mice (Fig. 10a). To validate changes in this pathway, we confirmed expression of two of the upregulated gene transcripts, Vcaml (z-score from -0.90 to 0.90 by RNAseq), and Cxcr4 (z-score from -0.89 to 0.89 by RNAseq) by real-time PCR in lysates obtained from hepatocyte-enriched cultures from a separate cohort of Asahl ${ }^{\mathrm{P} 361 \mathrm{R} / \mathrm{P} 361 \mathrm{R}}$ mice (Fig. 10c, d). We also evaluated inflammatory pathway activation by assessing STAT3 and NF-кB p65 phosphorylation in liver lysates from 5-weekold and 9-week-old Asahl ${ }^{+/+}$mice and Asahl $1^{\mathrm{P} 361 \mathrm{R} / \mathrm{P} 361 \mathrm{R}}$ mice by western blot (Fig. S6). No differences in STAT3 or $\mathrm{NF}-\kappa \mathrm{B}$ p65 phosphorylation were noted between liver tissue extracts from 5-week-old AsahI $1^{+/+}$mice and 5-week-old
Asahl ${ }^{\mathrm{P} 361 \mathrm{R} / \mathrm{P} 361 \mathrm{R}}$ mice (Figure S6). In 9-week-old mice, STAT3 phosphorylation was significantly increased in extracts from the livers of Asahl $1^{\mathrm{P} 361 \mathrm{R} / \mathrm{P} 361 \mathrm{R}}$ mice in comparison to $\mathrm{AsahI}^{+/+}$mice (Fig. S6).

The most significantly deactivated pathway in Asah1 $1^{\mathrm{P} 361 \mathrm{R} / \mathrm{P} 361 \mathrm{R}}$ mouse hepatocytes was the liver $\mathrm{X}$ receptor/retinoid $\mathrm{x}$ receptor (LXR/RXR) pathway (z-score -3.00; 18 of 121 genes significantly modified, $p$-value $=2.75 \times$ $10^{-12}$ ). Genes within this pathway play a role in the homeostasis of cholesterol and triglyceride metabolism. Within this pathway, a number of the apolipoprotein transcripts were downregulated (Fig. 10b); two of which were Apolipoprotein M (ApoM) (z-score from -0.83 to 0.83 by 
RNAseq) and Apolipoprotein A2 (ApoA2) (z-score from -0.76 to 0.76 by RNAseq) (Fig. 10b). The expression changes of both ApoM and ApoA2 were validated by realtime PCR in lysates from hepatocyte-enriched cultures obtained from a different cohort of animals (Fig. 10e, f).

\section{Discussion}

The clinical spectrum of ACDase deficiency in humans is broad. The most common clinical manifestations include subcutaneous nodules, joint contractures, and a hoarse voice. Beyond that, patients also develop neurological, respiratory, and other visceral disease. We have previously reported that our ACDase deficient mouse develops significant pathology within the hematopoietic, central nervous, and pulmonary systems [23, 25, 35]. In this report, we document liver pathology in this mouse. We further catalogue lipid and sphingolipid profiles and highlight changes in liver gene expression versus controls.

Within the limited medical literature on FD, the most typical hepatic sign is hepatomegaly in which the liver is often palpable during a clinical examination [1012, 36, 37]. In one of Dr. Sidney Farber's original case reports on three FD patients, he described the presence of hepatic necrosis, a faint cytoplasmic staining in both hepatocytes and Kupffer cells, and dilation of the liver sinuses [4]. Other postmortem reports demonstrated the presence of highly vacuolated atypical histiocytes [1, 37, 38]. Additionally, TEM analyses of liver biopsies from Farber patients revealed cells containing large intracytoplasmic inclusions, many of which contained low electron dense amorphous material [12, 39, 40]. The FD mouse model allows for a more detailed analyses of liver pathology than that which can be obtained from the limited human FD patient studies. Indeed, our analyses of livers from ACDase deficient mice are highly analogous to the pathology reported in FD patients. The livers of Asahl P361R/ P361R mice displayed significant fibrosis and inflammatory cell infiltration characterized by considerable storage pathology in recruited macrophages, resident Kupffer cells, and other cells within the liver sinusoid and portal areas (Fig. 2e). Similar observations have previously been reported in the spleen and thymus of Asahl $1^{\mathrm{P} 361 \mathrm{R} / \mathrm{P} 361 \mathrm{R}}$ mice [23].

Importantly, life-threatening liver failure has been reported to occur in neonates, infants, and juveniles affected by LSDs including acid sphingomyelinase deficiency [41, 42] and Niemann-Pick disease type C [43]. Liver enlargement and histiocytosis are common in classical FD, and severe liver pathology including organomegaly, and histiocytosis, has been documented in "visceral-neonate" cases, which usually do not live past 1 year of age [1]. Of the handful of case reports available, the presence of cholestatic jaundice, liver fibrosis, ascites, and liver injury have also been documented $[8,14,15]$. In one of these case reports, a 6-month-old infant that exhibited severe liver pathology was misdiagnosed with neonatal giant cell hepatitis. In this instance, proper diagnosis of FD was only achieved after the appearance of arthritic-like symptoms [8]. Cases such as these have expanded the clinical spectrum of $\mathrm{FD}$, where liver involvement may precede the appearance of more common FD symptoms such as nodule formation. The Asahl ${ }^{\mathrm{P} 361 \mathrm{R} / \mathrm{P} 361 \mathrm{R}}$ mouse displays significant liver pathology including an elevation of liver injury markers, progression of fibrosis, and cell death, similar to that seen in cases of visceral-neonate FD.

To investigate gene expression changes in the liver and potentially identify other therapeutic targets in Asahl ${ }^{\mathrm{P} 361 \mathrm{R} / \mathrm{P} 361 \mathrm{R}}$ mice, we performed RNAseq analysis. Since the liver contains various cell types, we wanted to approach this study using a uniform primary cell population. Skin fibroblasts were first considered; however, we ultimately decided to perfuse the liver and isolate hepatocytes as they are a more physiologically relevant cell type. We enriched for hepatocytes with the aim of studying both the sphingolipid profile and gene expression changes in the liver of Asahl ${ }^{\mathrm{P} 361 \mathrm{R} / \mathrm{P} 361 \mathrm{R}}$ mice. It should be noted that we analyzed hepatocyte cultures from 5-week-old animals for these experiments. This represents the mid-life timepoint for Asahl ${ }^{\mathrm{P} 361 \mathrm{R} / \mathrm{P} 361 \mathrm{R}}$ mice where they present with a much milder inflammatory phenotype than their older siblings. This timepoint may also afford an opportunity to see gene dysregulation that will contribute to the development of pathology in these mice.

Many gene transcripts were found significantly altered in cells from the hepatocyte-enriched Asahl ${ }^{\mathrm{P} 361 \mathrm{R} / \mathrm{P} 361 \mathrm{R}}$ cultures in comparison to controls (Fig. S5). Pathway analyses conducted on gene transcripts found significantly altered in Asahl $1^{\mathrm{P} 361 \mathrm{R} / \mathrm{P} 361 \mathrm{R}}$ mice revealed an upregulation of transcripts related to the inflammatory response. This was unsurprising as we have previously reported on increased inflammation in $A s a h 1^{\mathrm{P} 361 \mathrm{R} / \mathrm{P} 361 \mathrm{R}}$ mice [22, 24-26].

One of the upregulated genes in the leukocyte extravasation pathway that we validated with real-time PCR was Vcaml, a gene that functions in leukocyte-endothelial cell adhesion (Fig. 10a, c). We recently reported presence of chronic lung injury in the lungs of the Asahl $1^{\mathrm{P} 361 \mathrm{R} / \mathrm{P} 361 \mathrm{R}}$ mice. One of the findings from that study was a significant increase in vascular permeability in Asahl ${ }^{\mathrm{P} 361 \mathrm{R} / \mathrm{P} 361 \mathrm{R}}$ mice resulting in vascular leakage in various organs including the liver [25]. Upregulation of Vcaml in the liver may contribute to this observation and may partly explain the progressive infiltration of immune cells. Other genes we observed to be upregulated included CXCR4 and the chemokine CXCL12, which contribute to a wide range of 
biological functions [44]. Within the context of the liver, activation of CXCR4 signaling has been associated with the promotion of fibrosis [45]. Furthermore, targeting the CXCR4 pathway improves acute liver injury response and promotes liver regeneration [46]. In our mice, the presence of liver injury and progressive fibrosis may be related to these upregulated $C X C R 4$ levels.

RNAseq analyses has been used to study gene changes in other LSDs including profiling the cerebral cortex, midbrain, diencephalon, and hippocampus in a mouse model of MPSII [47] and investigating liver, lung, and spleen in a mouse model of Gaucher disease [48]. Neuroinflammation and Wnt signaling were some of the most significantly altered pathways in MPSII [47]. Inflammation, cell growth and proliferation, cell cycle, heme metabolism, and mitochondrial dysfunction were the most altered in Gaucher disease [48]. Immune activation has been reported in many LSD mouse models including MPS I [49], MPS II [47], MPS IIIA [49], MPS IIIB [49], MPS VII [50], GM2 gangliosidosis [51], Gaucher [51], and Niemann-Pick C [51]. This is not surprising as lysosomes are inherently important for many immune functions.

Interestingly, the lipid homeostasis pathway was significantly deactivated in our hepatocyte cultures, which may in part explain the reduction of TG and FFA noticed in both liver and serum samples (Fig. 6a, b, f, g). Asahl P361R/P361R mice begin to show a decrease in total body weight and lose fat around 5 weeks of age [22]. While we did not assess adipose tissue content per se, during necropsy we often saw an absence of fat pads in the visceral, anterior subcutaneous, and posterior subcutaneous regions (data not shown). Additionally, a number of case reports have reported progressive weight loss in FD [52-54]. One patient with the mild variant of FD was also described as lacking cutaneous fat [54]. One of the significantly downregulated pathways we identified was the LXR/RXR activation pathway, which plays a role in cholesterol absorption and excretion (Fig. 10b). Within this pathway, a number of genes for apolipoproteins were downregulated. ApoM and ApoA2 encode for lipoproteins found in high-density lipoprotein (HDL) particles. Deactivation of these pathways might contribute to the reduced free fatty acid and triglyceride levels in liver and serum in the Asahl $1^{\mathrm{P} 361 \mathrm{R} / \mathrm{P} 361 \mathrm{R}}$ mouse.

Disturbances in lipid homeostasis have been demonstrated in other animal models of sphingolipid pathway dysfunction. One study in the S1P lyase-deficient mouse demonstrated elevated lipid storage in both serum and liver, but decreased adiposity [55]. A report on the acid sphingomyelinase and LDL receptor double-deficient mouse demonstrated reduced hepatic TG accumulation and less fat accumulation compared to controls when animals were placed on a high-fat diet [56]. Studies have demonstrated the role of adiponectin regulation of ceramidase activity in the maintenance of insulin resistance [57-59], and that overexpressing ACDase in the liver led to improved insulin sensitivity and prevented hepatic steatosis in mice on a high-fat diet [60]. Most recently one study that performed transcriptome analyses on liver tissue from $\mathrm{CerS} 2$ deficient mice also revealed a significant downregulation in transcripts related to fatty acid oxidation [61]. Here we report downregulation of CerS2 expression (Fig. 9a, e) and a ceramide profile in the liver (Fig. 7a, f) similar to that in CerS2 mutant mice [62]. While more work will be required to understand this mechanism, these studies and ours collectively demonstrate that insults to the sphingolipid pathway can lead to similar functional consequences that cross over to other lipid metabolic pathways.

Lipidomic analyses of our liver lysates and hepatocyteenriched cultures revealed significant accumulation of total ceramide, SM, and MHC (Fig. 7a, b, d). Assessment of ceramide abundance revealed a proportional increase in the ratio of C16:0/SM16:0 acyl chain and C18:0/SM18:0 acyl chain sphingolipids and a reduction in the C22:0/SM22:0 acyl chain and C24:0/SM24:0 acyl chain sphingolipids in the liver of $A s a h 1^{\mathrm{P} 361 \mathrm{R} / \mathrm{P} 361 \mathrm{R}}$ mice (Fig. 7f). This alteration in long chain versus very long chain species ratios appears to be specific to the liver: our previous analyses of ceramides in the lung did not reveal such alterations in acyl chain composition $[25,26]$. As well, another of our studies on the brains of Asahl $1^{\mathrm{P} 361 \mathrm{R} / \mathrm{P} 361 \mathrm{R}}$ mice revealed the opposite: there was an increase in the $\mathrm{C} 24: 0$ species and a decrease in the $\mathrm{C} 18: 0$ species in Asahl ${ }^{\mathrm{P} 361 \mathrm{R} / \mathrm{P} 361 \mathrm{R}}$ mouse brains [35]. These differences in ceramide acyl chain distribution are partly due to the expression of the six CerS genes [29]. Our current data revealed a significant reduction in Cers2 and Cers4 transcripts in samples from Asahl $1^{\mathrm{P} 361 \mathrm{R} /}$ ${ }_{\text {P361R }}$ mice (Fig. 9a, e, f). Normal mice display high Cers 2 and Cers 4 expression in the liver [63]. Cers 2 is important for the synthesis of the very long chain ceramides, which include C20-C26 whereas Cers4 is important for the formation of C18-C22 ceramides [63]. Thus, decreased expression of Cers 2 and Cers 4 may partly explain the reduced abundance of $\mathrm{C} 22: 0$ and $\mathrm{C} 24: 0$ species we observed herein. Work on the Cers2-deficient mouse revealed a similar pattern wherein the $\mathrm{C} 16: 0$ species were significantly elevated to account for the reduction in C22:0 and C24:0 ceramides [64]. Analyses of the livers of those mice also revealed some similarities in liver pathology, such as increased cell death, increased expression of injury markers, inflammation, and fibrosis [62].

Ceramide is considered to be pro-apoptotic while S1P is considered to promote survival [65]. Particular to this rheostat is the role of C16:0 ceramide in the promotion of apoptosis [66]. One study demonstrated that overexpression of neutral ceramidase leads to a protective effect from TNF$\alpha$ induced apoptosis in rat hepatocytes [67]. Not only was 
C16:0 reduced, but also an increase in S1P levels was detected [67]. Another report showed that knockdown of Cers 2 led to increased cell death in HeLa cells treated with cisplatin and a shift in sphingolipid composition from C24:0 to C16:0 [68]. With respect to our study, the increased cell death noted may be in part due to the increased abundance of C16:0 ceramide. We also detected significantly increased $\mathrm{SM}$ in Asahl $^{\mathrm{P} 361 \mathrm{R} / \mathrm{P} 361 \mathrm{R}}$ mouse liver lysates, possibly the result of defective ceramide breakdown (Fig. 7b).

Lastly, we demonstrated a significant upregulation of Cerk and Ugcg transcripts (Fig. 9a, b, d). Cerk converts ceramide to C1P, and $U g c g$ is an important enzyme in the biosynthesis of glucosylceramides [17]. This upregulation may explain the increased level of MHC and C1P in liver lysates that we observed (Fig. 7d, e). In fact, secondary lipid accumulation is a common observation seen in other LSDs $[69,70]$. One example is the accumulation of gangliosides in Niemann-Pick disease type C (NPC)-deficient mice [71]. A possible explanation for this phenomenon is that the impairment of the endosomal/lysosomal system caused by the primary genetic defect results in accumulation of gangliosides [70]. This sequestration leads to a state of starvation within a cell that could lead to upregulation of genes responsible for glycosphingolipid synthesis [70]. As ceramide is central to the formation of more complex sphingolipids, the upregulation of $C e r K$ and $U g c g$ could be due to such a mechanism.

Additionally, we noted upregulation of Psap, which encodes for a precursor glycoprotein that is cleaved into four sphingolipid activator proteins collectively called saposins A-D (Fig. 9a, c) [72]. Since saposin D acts as a stimulant for ACDase, it is possible that an increase in Psap is stimulated in order to boost enzyme effectiveness [73]. Additionally, as a pan increase in sphingolipids was detected, upregulation of Psap may impact the activity of other sphingolipid metabolizing enzymes. Not surprisingly, transcription factor EB (TFEB), a master lysosomal regulator that is elevated in numerous LSDs, was also found upregulated (Table S3). Taken together, these results demonstrate that mutations to Asahl not only lead to sphingolipid buildup, but also to significant alteration in genes that control sphingolipid homeostasis.

Our study has provided a comprehensive analysis of hepatic pathology in the ACDase deficient mouse. We have highlighted parallels between human cases and our model for liver injury, inflammation, and ultrastructure pathology. With limited availability of FD patient tissues, our Asahl $1^{\mathrm{P} 361 \mathrm{R} / \mathrm{P} 361 \mathrm{R}}$ mouse model has aimed to fill this gap by allowing pathological and molecular study of acid ceramidase deficiency. Our findings provide the first insight into the pathology and perturbed metabolic regulation present in the liver of acid ceramidase-deficient mice.
Acknowledgements We thank the staff at The Centre for Phenogenomics (TCP), the Centre for Modeling Human Diseases (CMHD) Pathology Core in Toronto, and the Children's Hospital of Wisconsin (CHW) Children's Research Institute (CRI) Histology and Imaging Cores for technical assistance with histology services. We also thank the Advanced Optical Microscopy Facility (AOMF) at the University Health Network for providing whole-slide scanning for pathology analysis. The electron microscopic analyses were supported by the OPPK (CZ.2.16/3.1.00/24509), NCMG LM2015091 projects and by the Charles University Institutional Research and Development schemes PRVOUK P24 and PROGRESS Q26. The rest of the studies were supported by the MACC Fund Professorship awarded to JAM. The authors would also like to acknowledge Aaron Schuett from Pewaukee Veterinary Service for assistance with biochemical analyses.

\section{Compliance with ethical standards}

Conflict of interest The authors declare that they have no conflict of interest.

Publisher's note: Springer Nature remains neutral with regard to jurisdictional claims in published maps and institutional affiliations.

\section{References}

1. Levade T, Sandhoff K, Schulze H, Medin JA. Acid ceramidase deficiency: Farber lipogranulomatosis. In: Valle D, Beaudet AL, Vogelstein B, Kinzler KW, Antonarakis SE, Ballabio A, editors. Scriver's OMMBID (Online Metabolic and Molecular Basis of Inherited Diseases). New York: McGraw-Hill, 2014.

2. Yu F, Amintas S, Levade T, Medin JA. Acid ceramidase deficiency: Farber disease and SMA-PME. Orphanet J Rare Dis. 2018;13:121.

3. Zielonka M, Garbade SF, Kölker S, Hoffmann GF, Ries M. A cross-sectional quantitative analysis of the natural history of farber disease: An ultra-orphan condition with rheumatologic and neurological cardinal disease features. Genet Med. 2017;20:524-530.

4. Farber S, Cohen J, Uzman LL. Lipogranulomatosis; a new lipoglycoprotein storage disease. J Mt Sinai Hosp NY. 1957;24: 816-837.

5. Ehlert K, Frosch M, Fehse N, Zander A, Roth J, Vormoor J. Farber disease: Clinical presentation, pathogenesis and a new approach to treatment. Pediatr Rheumatol. 2007;5:15-22.

6. Kim SY, Choi SA, Lee S, Lee JS, Hong CR, Lim BC. Atypical presentation of infantile-onset farber disease with novel ASAH1 mutations. Am J Med Genet. 2016;170:3023-3027.

7. Zetterström R. Disseminated lipogranulomatosis (farber's disease). Acta Paediatr. 1958;47:501-510.

8. Salo MK, Karikoski R, Hällström M, Jalanko H, Holmberg C. Farber disease diagnosed after liver transplantation. J Pediatr Gastroenterol Nutr. 2003;36:274-277.

9. Ehlert K, Roth J, Frosch M, Fehse N, Zander N, Vormoor J. Farber's disease without central nervous system involvement: Bone-marrow transplantation provides a promising new approach. Ann Rheum Dis. 2006;65:1665-1666.

10. Abul-Haj SK, Martz DG, Douglas WF, Geppert LJ. Farber's disease: Report of a case with observations on its histogenesis and notes on the nature of the stored material. J Pediatr. 1962;61: 221-232.

11. Samuelsson K, Zetterström R. Ceramides in a patient with lipogranulomatosis (farber's disease) with chronic course. Scand J Clin Lab Invest. 1971;27:393-405. 
12. Tanaka T, Takahashi K, Hakozaki H, Kimoto H, Suzuki Y. Farber's disease (disseminated lipogranulomatosis) A pathological, histochemical and ultrastructural study. Pathol Int. 1979;29: 135-155.

13. Antonarakis S, Valle D, Moser H, Zinkham W, Qualman S. Farber's lipogranulomatosis: Variability of expression and clinical overlap with histiocytosis. Pediatr Res. 1983;17:206A.

14. Willis A, VanHuse C, Newton KP, Wasserstein M, Morotti RA. Farber's disease type IV presenting with cholestasis and neonatal liver failure: Report of two cases. Pediatr Dev Pathol. 2008;11: 305-308.

15. Nowaczyk M, Feigenbaum A, Silver MM, Callahan J, Levin A, Jay V. Bone marrow involvement and obstructive jaundice in farber lipogranulomatosis: Clinical and autopsy report of a new case. J Inherit Metab Dis. 1996;19:655-660.

16. Coant N, Sakamoto W, Mao C, Hannun YA. Ceramidases, roles in sphingolipid metabolism and in health and disease. Advances in biological regulation. 2017;63:122-131.

17. Hannun YA, Obeid LM. Sphingolipids and their metabolism in physiology and disease. Nat Rev Mol Cell Biol. 2017;19:175-191.

18. Matsuda J, Suzuki O, Oshima A, Ogura A, Noguchi Y, Yamamoto $\mathrm{Y}$, et al. Beta-galactosidase-deficient mouse as an animal model for GM1-gangliosidosis. Glycoconj J. 1997;14:729-736.

19. García-Ruiz C, Colell A, Marí M, Morales A, Calvo M, Enrich C, et al. Defective TNF- $\alpha$-mediated hepatocellular apoptosis and liver damage in acidic sphingomyelinase knockout mice. J Clin Invest. 2003;111:197-208.

20. Mistry PK, Liu J, Yang M, Nottoli T, McGrath J, Jain D, et al. Glucocerebrosidase gene-deficient mouse recapitulates gaucher disease displaying cellular and molecular dysregulation beyond the macrophage. Proc Natl Acad Sci U S A. 2010;107: 19473-19478.

21. Jennemann R, Rothermel U, Wang S, Sandhoff R, Kaden S, Out $\mathrm{R}$, et al. Hepatic glycosphingolipid deficiency and liver function in mice. Hepatology. 2010;51:1799-1809.

22. Alayoubi AM, Wang JC, Au BC, Carpentier S, Garcia V, Dworski $\mathrm{S}$, et al. Systemic ceramide accumulation leads to severe and varied pathological consequences. EMBO Mol Med. 2013;5: 827-842.

23. Dworski S, Berger A, Furlonger C, Moreau JM, Yoshimitsu M, Trentadue $\mathrm{J}$, et al. Markedly perturbed hematopoiesis in acid ceramidase deficient mice. Haematologica. 2015;100:162-165.

24. Dworski S, Lu P, Khan A, Maranda B, Mitchell JJ, Parini R, et al. Acid ceramidase deficiency is characterized by a unique plasma cytokine and ceramide profile that is altered by therapy. Biochim Biophys Acta Mol Cell Biol Lipids. 2017;1863:386-394.

25. Yu FP, Islam D, Sikora J, Dworski S, Gurka J, López-Vásquez L, et al. Chronic lung injury and impaired pulmonary function in a mouse model of acid ceramidase deficiency. Am J Physiol Lung Cell Mol Physiol. 2017;314:406-420.

26. Yu FPS, Dworski S, Medin JA. Deletion of MCP-1 impedes pathogenesis of acid ceramidase deficiency. Sci Rep. 2018;8:1808.

27. Futerman AH, Hannun YA. The complex life of simple sphingolipids. EMBO Rep. 2004;5:777-782.

28. Hannun YA, Obeid LM. Principles of bioactive lipid signalling: Lessons from sphingolipids. Nat Rev Mol Cell Biol. 2008;9:139-150.

29. Mullen TD, Hannun YA, Obeid LM. Ceramide synthases at the centre of sphingolipid metabolism and biology. Biochem J. 2012;441:789-802.

30. Adams JM, Pratipanawatr T, Berria R, Wang E, DeFronzo RA, Sullards MC, et al. Ceramide content is increased in skeletal muscle from obese insulin-resistant humans. Diabetes. 2004;53: 25-31.

31. Yang G, Badeanlou L, Bielawski J, Roberts AJ, Hannun YA, Samad F, et al. Central role of ceramide biosynthesis in body weight regulation, energy metabolism, and the metabolic syndrome. Am J Physiol Endocrinol Metab. 2009;297:211-224.

32. Azuma H, Paulk N, Ranade A, Dorrell C, Al-Dhalimy M, Ellis E. Robust expansion of human hepatocytes in $\mathrm{fah}^{-/-} / \mathrm{Rag}^{-/-}$/ Il2 $\mathrm{rg}^{-1-}$ mice. Nat Biotechnol. 2007;25:903-910.

33. Bielawski J, Pierce JS, Snider J, Rembiesa B, Szulc ZM, Bielawska A. Sphingolipid analysis by high performance liquid chromatography-tandem mass spectrometry (HPLC-MS/MS). Adv Exp Med Biol. 2010;688:46-59.

34. Lee SM, Schelcher C, Demmel M, Hauner M, Thasler WE. Isolation of human hepatocytes by a two-step collagenase perfusion procedure. J Vis Exp. 2013;79:e50615.

35. Sikora J, Dworski S, Jones EE, Kamani MA, Micsenyi MC, Sawada T, et al. Acid ceramidase deficiency in mice results in a broad range of central nervous system abnormalities. Am J Pathol. 2017; 187:864-883.

36. Farber S. A lipid metabolic disorder: Disseminated lipogranulomatosis; a syndrome with similarity to, and important difference from, niemann-pick and hand-schuller-christian disease. AMA Am J Dis Child. 1952;84:499-500.

37. Antonarakis S, Valle D, Moser HW, Moser A, Qualman SJ, Zinkham WH. Phenotypic variability in siblings with farber disease. J Pediatr. 1984;104:406-409.

38. Bao XH, Tian JM, Ji TY, Chang XZ. A case report of childhood farber's disease and literature review. Zhonghua $\mathrm{Er} \mathrm{Ke} \mathrm{Za} Z \mathrm{Zhi}$. 2017;55:54-58.

39. Hoof Fv, Hers HG. The abnormalities of lysosomal enzymes in mucopolysaccharidoses. FEBS J. 1968;7:34-44.

40. Abenoza P, Sibley RK. Farber's disease: A fine structural study. Ultrastruct Pathol. 1987;11:397-403.

41. Pavlů-Pereira H, Asfaw B, Poupčtová H, Ledvinová J, Sikora J, Vanier MT, et al. Acid sphingomyelinase deficiency phenotype variability with prevalence of intermediate phenotype in a series of twenty-five czech and slovak patients. A multi-approach study. J Inherit Metab Dis. 2005;28:203-227.

42. McGovern MM, Lippa N, Bagiella E, Schuchman EH, Desnick RJ, Wasserstein MP. Morbidity and mortality in type B Niemann-Pick disease. Genet Med. 2013;15:618-623.

43. Vanier MT. Niemann-Pick disease type C. Orphanet J Rare Dis. 2010;5:16.

44. Domanska UM, Kruizinga RC, Nagengast WB, Timmer-Bosscha $\mathrm{H}$, Huls G, de Vries EG, et al. A review on CXCR4/CXCL12 axis in oncology: No place to hide. Eur J Cancer. 2013;49:219-230.

45. Hong F, Tuyama A, Lee TF, Loke J, Agarwal R, Cheng X, et al. Hepatic stellate cells express functional CXCR4: Role in stromal cell-derived factor- $1 \alpha$-mediated stellate cell activation. Hepatology. 2009;49:2055-2067.

46. Wilson GC, Freeman CM, Kuethe JW, Quillin RC, Nojima H, Schuster R, et al. CXC chemokine receptor-4 signaling limits hepatocyte proliferation after hepatic ischemia-reperfusion in mice. Am J Physiol-Gastr L. 2015;308:702-709.

47. Salvalaio M, D'Avanzo F, Rigon L, Zanetti A, D'Angelo M, Valle $\mathrm{G}$, et al. Brain RNA-seq profiling of the mucopolysaccharidosis type II mouse model. Int J Mol Sci. 2017;18:1072.

48. Dasgupta N, Xu Y, Oh S, Sun Y, Jia L, Keddache M, et al. Gaucher disease: Transcriptome analyses using microarray or mRNA sequencing in a Gbal mutant mouse model treated with velaglucerase alfa or imiglucerase. PloS One. 2013;8:e74912.

49. Wilkinson FL, Holley RJ, Langford-Smith KJ, Badrinath S, Liao A, Langford-Smith A, et al. Neuropathology in mouse models of mucopolysaccharidosis type I, IIIA and IIIB. PloS One. 2012;7: e35787.

50. Archer LD, Langford-Smith KJ, Bigger BW, Fildes JE. Mucopolysaccharide diseases: A complex interplay between neuroinflammation, microglial activation and adaptive immunity. J Inherit Metab Dis. 2014;37:1-12. 
51. Vitner EB, Futerman AH, Platt N. Innate immune responses in the brain of sphingolipid lysosomal storage diseases. Biol Chem. 2015;396:659-667.

52. Ozaki H, Mizutani M, Hayashi H, Oka E, Ohtahara S, Kimoto H, et al. Farber's disease (disseminated lipogranulomatosis): The first case reported in japan. Acta Med Okayama. 1978;32:69-79.

53. Amirhakimi GH, Haghighi P, Ghalambor MA, Honari S. Familial lipogranulomatosis (farber's disease). Clin Genet. 1976;9:625-630.

54. Fiumara A, Nigro F, Pavone L, Moser HW. Farber disease with prolonged survival. J Inherit Metab Dis. 1993;16:915-916.

55. Bektas M, Allende ML, Lee BG, Chen W, Amar MJ, Remaley AT, et al. Sphingosine 1-phosphate lyase deficiency disrupts lipid homeostasis in liver. J Biol Chem. 2010;285:10880-10889.

56. Deevska GM, Rozenova KA, Giltiay NV, Chambers MA, White $\mathrm{J}$, Boyanovsky BB, et al. Acid sphingomyelinase deficiency prevents diet-induced hepatic triacylglycerol accumulation and hyperglycemia in mice. J Biol Chem. 2009;284:8359-8368.

57. Summers SA, Nelson DH. A role for sphingolipids in producing the common features of type 2 diabetes, metabolic syndrome $\mathrm{X}$, and cushing's syndrome. Diabetes. 2005;54:591-602.

58. Holland WL, Brozinick JT, Wang L, Hawkins ED, Sargent KM, Liu Y, et al. Inhibition of ceramide synthesis ameliorates glucocorticoid-, saturated-fat-, and obesity-induced insulin resistance. Cell Metab. 2007;5:167-179.

59. Holland WL, Miller RA, Wang ZV, Sun K, Barth BM, Bui HH, et al. Receptor-mediated activation of ceramidase activity initiates the pleiotropic actions of adiponectin. Nat Med. 2011;17:55-63.

60. Xia JY, Holland WL, Kusminski CM, Sun K, Sharma AX, Pearson MJ, et al. Targeted induction of ceramide degradation leads to improved systemic metabolism and reduced hepatic steatosis. Cell Metab. 2015;22:266-278.

61. Bickert A, Kern P, van Uelft M, Herresthal S, Ulas T, Gutbrod K, et al. Inactivation of ceramide synthase 2 catalytic activity in mice affects transcription of genes involved in lipid metabolism and cell division. Biochim Biophys Acta Mol Basis Dis. 2018;1863: 734-749.

62. Pewzner-Jung Y, Brenner O, Braun S, Laviad EL, Ben-Dor S, Feldmesser E, et al. A critical role for ceramide synthase 2 in liver homeostasis II. insights into molecular changes leading to hepatopathy. J Biol Chem. 2010;285:10911-10923.

63. Levy M, Futerman AH. Mammalian ceramide synthases. IUBMB Life. 2010;62:347-356.

64. Pewzner-Jung Y, Park H, Laviad EL, Silva LC, Lahiri S, Stiban J, et al. A critical role for ceramide synthase 2 in liver homeostasis: I. Alterations in lipid metabolic pathways. J Biol Chem. 2010;285:10902-10910.

65. Maceyka M, Payne SG, Milstien S, Spiegel S. Sphingosine kinase, sphingosine-1-phosphate, and apoptosis. Biochim Biophys Acta Mol Cell Biol Lipids. 2002;1585:193-201.

66. Thomas RL, Matsko CM, Lotze MT, Amoscato AA. Mass spectrometric identification of increased C16 ceramide levels during apoptosis. J Biol Chem. 1999;274:30580-30588.

67. Osawa Y, Uchinami H, Bielawski J, Schwabe RF, Hannun YA, Brenner DA. Roles for C16-ceramide and sphingosine 1phosphate in regulating hepatocyte apoptosis in response to tumor necrosis factor- $\alpha$. J Biol Chem. 2005;280:27879-27887.

68. Sassa T, Suto S, Okayasu Y, Kihara A. A shift in sphingolipid composition from $\mathrm{C} 24$ to $\mathrm{C} 16$ increases susceptibility to apoptosis in HeLa cells. Biochim Biophys Acta Mol Cell Biol Lipids. 2012;1821:1031-1037.

69. Walkley SU. Secondary accumulation of gangliosides in lysosomal storage disorders. Semin Cell Dev Biol. 2004;15:433-444.

70. Walkley SU, Vanier MT. Secondary lipid accumulation in lysosomal disease. Biochimica et Biophysica Acta Mol Cell Res. 2009;1793:726-736.

71. Zhou S, Davidson C, McGlynn R, Stephney G, Dobrenis K, Vanier MT, et al. Endosomal/lysosomal processing of gangliosides affects neuronal cholesterol sequestration in Niemann-Pick disease type C. Am J Pathol. 2011;179:890-902.

72. radova V, Šmíd F, Ulrich-Bott B, Roggendorf W, Paton BC, Harzer K. Prosaposin deficiency: Further characterization of the sphingolipid activator protein-deficient sibs. Hum Genet. 1993;92: $143-152$.

73. Azuma N, Obrien JS, Moser HW, Kishimoto Y. Stimulation of acid ceramidase activity by saposin D. Arch Biochem Biophys. 1994;311:354-357. 